\title{
Asia-Pacific consensus on the management of gastro-oesophageal reflux disease: an update focusing on refractory reflux disease and Barrett's oesophagus
}

\author{
Kwong Ming Fock, ${ }^{1}$ Nicholas Talley, ${ }^{2}$ Khean Lee Goh, ${ }^{3}$ Kentaro Sugano, ${ }^{4}$ \\ Peter Katelaris, ${ }^{5}$ Gerald Holtmann, ${ }^{6}$ John E Pandolfino, ${ }^{7}$ Prateek Sharma, ${ }^{8}$ \\ Tiing Leong Ang, ${ }^{1}$ Michio Hongo, ${ }^{9}$ Justin Wu, ${ }^{10}$ Minhu Chen, ${ }^{11}$ Myung-Gyu Choi, ${ }^{12}$ \\ Ngai Moh Law, ${ }^{1}$ Bor-Shyang Sheu, ${ }^{13}$ Jun Zhang, ${ }^{14}$ Khek Yu Ho, $^{15}$ Jose Sollano, ${ }^{16}$ \\ Abdul Aziz Rani, ${ }^{17}$ Chomsri Kositchaiwat, ${ }^{18}$ Shobna Bhatia ${ }^{19}$
}

For numbered affiliations see end of article.

\section{Correspondence to} Professor Kwong Ming Fock, Department of Gastroenterology and Hepatology, Changi General Hospital, 2 Simei Street 3, Singapore 529889, Singapore; Kwong_ming_fock@cgh. com.sg

Received 23 February 2016 Revised 13 May 2016 Accepted 15 May 2016 Published Online First 3 June 2016

\section{ABSTRACT}

Objective Since the publication of the Asia-Pacific consensus on gastro-oesophageal reflux disease in 2008, there has been further scientific advancement in this field. This updated consensus focuses on proton pump inhibitor-refractory reflux disease and Barrett's oesophagus.

Methods A steering committee identified three areas to address: (1) burden of disease and diagnosis of reflux disease; (2) proton pump inhibitor-refractory reflux disease; (3) Barrett's oesophagus. Three working groups formulated draft statements with supporting evidence. Discussions were done via email before a final face-toface discussion. We used a Delphi consensus process, with a 70\% agreement threshold, using Grading of Recommendations Assessment, Development and Evaluation (GRADE) criteria to categorise the quality of evidence and strength of recommendations.

Results A total of 32 statements were proposed and 31 were accepted by consensus. A rise in the prevalence rates of gastro-oesophageal reflux disease in Asia was noted, with the majority being non-erosive reflux disease. Overweight and obesity contributed to the rise. Proton pump inhibitor-refractory reflux disease was recognised to be common. A distinction was made between refractory symptoms and refractory reflux disease, with clarification of the roles of endoscopy and functional testing summarised in two algorithms. The definition of Barrett's oesophagus was revised such that a minimum length of $1 \mathrm{~cm}$ was required and the presence of intestinal metaplasia no longer necessary. We recommended the use of standardised endoscopic reporting and advocated endoscopic therapy for confirmed dysplasia and early cancer.

Conclusions These guidelines standardise the management of patients with refractory gastrooesophageal reflux disease and Barrett's oesophagus in the Asia-Pacific region.

\section{INTRODUCTION}

Most gastro-oesophageal reflux disease (GORD) is non-erosive reflux disease (NERD), with the remainder being erosive reflux disease (ERD) of varying severity and complications including Barrett's oesophagus (BO), stricture and oesophageal adenocarcinoma (OAC), which are uncommon to rare in many parts of the Asia-Pacific region. Prior to 2004, GORD was considered to be uncommon in Asian populations compared with Western populations. In 2004 the Asia-Pacific consensus on the management of GORD recognised that there was an increasing frequency of the disease in Asia and reviewed the diagnostic and therapeutic modalities that were available in the region. A second consensus was then published as atypical, and extra-oesophageal manifestations of GORD were diagnosed increasingly and surgical and endoscopic treatment became more readily available. Currently, a third review of GORD management was deemed necessary to address the issue of proton pump inhibitor (PPI)-refractory GORD and to review new modalities that have emerged for diagnosis of $\mathrm{BO}$ with new recommendations for screening and surveillance.

\section{METHODS}

\section{Membership of the consensus panel}

A steering committee comprising three clinicians (KMF, KLG, KS) was appointed by the Asian Pacific Association of Gastroenterology (APAGE). The steering committee in turn nominated members regarded as experts in the field of GORD to form the faculty of the working groups. Faculty members were assigned clinical questions (CQ) for which they were to develop statements with supporting evidence. Two members of each group served as moderators. In addition, two international members provided their perspectives but did not participate in the voting.

\section{Literature search and consensus development process}

An initial literature search was performed by the steering committee using guidelines from the USA, ${ }^{1}{ }^{2} \mathrm{Asia}^{3}{ }^{4}$ and the $\mathrm{UK}^{5}$ to identify current issues in epidemiology, diagnosis and treatment of GORD. The topics identified were grouped under: (1) burden of disease and diagnosis of GORD; (2) PPI-refractory GORD; (3) BO. Based on the issues identified, three working groups were formed. Drafts of CQ about each topic were prepared by the steering committee and circulated to the 
working groups. These working groups conducted a further extensive literature search for relevant English articles up to July 2014 and formulated initial draft statements with supporting evidence. The references of both updated published guidelines and original articles were additionally reviewed to identify pertinent literature. The focus was on Asian data, but where such data were not available or weak, Western data were reviewed and the results extrapolated for use in the Asia-Pacific context. Initial discussions were done via email with the secretariat keeping track of the progress. The working parties then gathered at a two-day meeting in Singapore (2-3 August 2014) to seek consensus on the statements. At the consensus meeting there was presentation of the relevant data, face-to-face discussion and voting of the finalised statements. All votes were anonymous. We used a Delphi consensus process, with a $70 \%$ agreement threshold, using GRADE criteria (Grading of Recommendations Assessment, Development and Evaluation) to categorise the quality of evidence and strength of recommendations. ${ }^{6}$ Evidence was graded as high, moderate or low and recommendations were graded as strong or weak. Based on the consensus outcome, a manuscript was drafted by each group and then edited by the steering committee and referred to the entire group for input. Relevant literature pertinent to the discussion up to December 2015 was additionally incorporated. A total of 32 statements were proposed and 31 reached consensus.

\section{RESULTS}

\section{Burden of disease and diagnosis}

CQ1. How is the prevalence of typical GORD in a community determined?

\section{Statement 1}

Both symptomatic GORD and endoscopic oesophagitis can be used as measures to define the prevalence of GORD in the community.

Agreement: $94.7 \%$

Quality of evidence: Not applicable (NA)

Strength of recommendation: NA

There are two practical ways of determining the burden of disease: (1) prevalence of GORD symptoms; and (2) prevalence of endoscopic oesophagitis, which includes both ERD and complications associated with GORD. Each measurement has its drawbacks, but they remain the best ways of quantifying disease. Measurement of GORD symptoms in the population is based on the subject's response, such as frequency of predominant symptoms of heartburn and regurgitation, and GORD questionnaires. Few studies are strictly community-based. Endoscopic oesophagitis is an objective measure based on subjects undergoing endoscopy for symptom evaluation or screening.

CQ2. Are there changes in the epidemiology of erosive and non-erosive reflux oesophagitis in the Asia-Pacific region?

Statement $2 a$

The prevalence of GORD is increasing in the Asia-Pacific region.

Agreement: $100 \%$

Quality of evidence: Moderate

Strength of recommendation: NA

Two recent population-based studies from the region reported a high prevalence of GORD in the community with rates of $25 \%$ and $18.7 \% .^{7}{ }^{8}$ These studies from Taiwan ${ }^{7}$ and India ${ }^{8}$ were population-based studies that used validated GORD questionnaires. The prevalence in the Taiwan study was higher than previously reported, which was as low as $3.9 \% .{ }^{9}$ Another study of asymptomatic health screening subjects from Taiwan showed a prevalence rate of $12.0 \% .^{10}$ Chen et al ${ }^{11}$ reported an increase in the prevalence of ERD in referred patients (from $20.7 \%$ in 2000 to $51.0 \%$ in 2007) as well as health screening subjects (from $14.5 \%$ in 2004 to $23.5 \%$ in 2007 ) in a tertiary care centre from Taiwan. A multicentre study from the Indian Society of Gastroenterology Task Force showed a prevalence of $7.6 \%,{ }^{12}$ while other regional studies in India reported a prevalence of the order of $18.7 \% .^{13}$ A population-based survey from five regions in China showed that the prevalence of symptomatic GORD was $3.1 \%$ and varied significantly among the five regions (from $1.7 \%$ in Guangzhou to $5.1 \%$ in Wuhan) and between rural and urban populations. ${ }^{14}$ In Shanghai the estimated prevalence was $6.4 \% .{ }^{15}$ A nationwide study on reflux oesophagitis in China yielded a prevalence of $17.8 \%{ }^{16} \mathrm{Kim}$ et $a l^{17}$ reviewed National Health Insurance statistics for Korea and showed an increase in the diagnosis of GORD from $4.59 \%$ in 2005 to $7.27 \%$ in 2009 .

\section{Statement $2 b$}

NERD remains the commonest manifestation of GORD in the Asia-Pacific region.

Agreement: $100 \%$

Quality of evidence: Strong

Strength of recommendation: NA

Although there was an increase in ERD in the Asia-Pacific region, NERD remained at $78-93 \%$ of all reflux disease. ${ }^{18}$

\section{Statement 2c}

The severity of ERD remains mild.

Agreement: $100 \%$

Quality of evidence: Strong

Strength of recommendation: NA

The severity of ERD remained mild with the majority of patients having Los Angeles (LA) Grade A oesophagitis (50-90\%). ${ }^{18}$

CQ3. What are the factors that have caused the change in epidemiology of erosive and non-erosive oesophagitis?

Statement $3 a$

Increasing prevalence of overweight and obesity in the Asia-Pacific region is likely to have contributed to the increase in GORD.

Agreement: $100 \%$

Quality of evidence: Low

Strength of recommendation: NA

A meta-analysis of studies in the USA and Europe showed a close relationship between overweight, obesity and GORD. Studies from the USA demonstrated that overweight and obesity were significantly associated with GORD, with ORs of 1.57 (95\% CI 1.36 to 1.80 ) and 2.15 (95\% CI 1.89 to 2.45), respectively. ${ }^{19}$ In 14 countries in the Asia-Pacific region, an increase in the prevalence of overweight has been demonstrated, ranging from $5 \%$ in India to $60 \%$ in Australia. ${ }^{20}$ Body mass index (BMI) $\geq 25$ (OR 1.90; 95\% CI 1.4 to 2.6 ) was associated with the presence of GORD symptoms in employees of a large hospital in India. ${ }^{21}$ In a nationwide multicentre prospective study in Korea, BMI $\geq 25$ was associated with OR of 1.3 (CI 1.05 to 1.52 ) for ERD. The study further demonstrated that, for BMI $<23$ and NERD, the OR was 1.2 (95\% CI 1.06 to 1.41$){ }^{22}$ Data from Taiwan in asymptomatic subjects undergoing a health check-up revealed that BMI 25-30 (OR 2.3; 95\% CI 1.3 to 4.2) and BMI 
$>30$ (OR 3.8; 95\% CI 1.3 to 10.9 ) were independent predictors of ERD. ${ }^{10}$

\section{Statement $3 b$}

The decline in Helicobacter pylori infection is unlikely to have a major role in the increase in the prevalence of GORD.

Agreement: $68.4 \%$

Quality of evidence: Moderate

Strength of recommendation: NA

Epidemiological studies show an association between lower H. pylori prevalence and higher rates of reflux disease, although this has not been established to be causal. ${ }^{23-27}$ H. pylori infection was associated with a decrease in the prevalence of ERD in two Japanese studies (OR 0.35 ; $95 \%$ CI 0.30 to 0.40 and OR 0.58 ; $95 \%$ CI 0.44 to 0.76 , respectively) ${ }^{23} 24$ and in Korea (OR $0.44 ; 95 \%$ CI 0.39 to 0.49$).{ }^{27}$ Data for migrants from Vietnam to Australia show an increase in ERD in migrants compared with non-migrants while both groups had identical H. pylori infection rates, suggesting lifestyle factors as the key determinant of GORD. ${ }^{26}$ Therefore, an inverse association between $H$. pylori and the prevalence of reflux does not prove a cause and effect relationship.

\section{CQ4. What are the data on the epidemiology of} extra-oesophageal manifestations of GORD in Asia?

\section{Statement 4}

Data on the prevalence of extra-oesophageal manifestations of GORD in Asia are limited, but it is likely to be uncommon.

Agreement: $84.2 \%$

Quality of evidence: Low

Strength of recommendation: NA

There are only sporadic data on rates of extra-oesophageal manifestations of GORD in Asia. A systematic review of Asian publications that examined asthma, sleep disturbance, temporomandibular joint dysfunction, dental erosions, non-cardiac chest pain (NCCP) and chronic laryngitis ${ }^{28}$ showed a wide range of prevalence among the 17 collated studies. Few population data are available to determine regional prevalence rates. In general, the prevalence of extra-oesophageal manifestations of GORD increases with an increasing burden of GORD in a population. Two small population-based studies from Korea ${ }^{29}$ and China ${ }^{30}$ showed this association between symptomatic GORD and extraoesophageal manifestations.

\section{CQ5. Should the diagnosis of BO be based on endoscopic diagnosis or is histological confirmation required? \\ Statement 5}

The term endoscopic columnar lined oesophagus should be used to describe proximal appearing columnar epithelium in the distal oesophagus. Histological confirmation is required and aids in the stratification of risk.

Agreement: 94.7\%

Quality of evidence: NA

Strength of recommendation: Strong

$\mathrm{BO}$ remains an uncommon diagnosis in much of the Asia-Pacific region. Outside Japan, the prevalence of $\mathrm{BO}$ was reported to be in the range of $0.06-6.2 \% .^{31} 32$ The group agreed that histological confirmation is required but intestinal metaplasia (IM) is not a prerequisite for diagnosis as the definition of BO is of proximal appearing columnar lined oesophagus in the distal oesophagus at endoscopy, confirmed by histology. Further details about controversies in the diagnostic criteria for BO are discussed in Statement 21.
CQ6. How should the BO epidemiology data be expressed (as a percentage of GORD diagnosed on endoscopy or a percentage of all endoscopies)?

\section{Statement 6}

The prevalence of BO may be determined from health screening endoscopy studies and investigations of symptomatic patients.

Agreement: 100\%

Quality of evidence: NA

Strength of recommendation: Strong

The prevalence of BO when expressed as a proportion of all patients who underwent endoscopy is a crude measure for comparison between regions as the indication for and availability of endoscopy varies so widely. Prevalence expressed as a proportion of those presenting for endoscopy with reflux symptoms and having ERD diagnosed determine prevalence in those presenting with symptoms. This would allow some comparison within the region. ${ }^{31} 32$ Prevalence from health screening endoscopy studies will provide better population data. There are several studies available from some regions (although most are directed towards gastric cancer screening). There are still inherent selection biases in such studies, but such surveys do provide more accurate data at the population level. A crude overall population prevalence figure would be useful but requires random population endoscopy studies and few of these are available.

CQ7. In patients with NCCP, should diagnostic evaluation with endoscopy and $\mathrm{pH}$ monitoring precede therapy?

Statement 7

A therapeutic trial of PPI is the most pragmatic approach for suspected GORD-related NCCP owing to the low sensitivity of endoscopy and limited access to $\mathrm{pH}$ monitoring.

Agreement: $89.5 \%$

Quality of evidence: Moderate

Strength of recommendation: Strong

NCCP is the presenting symptom in about $10 \%$ of patients with GORD. ${ }^{33}$ The diagnostic yield of endoscopy for NCCP is low as ERD is present in $<10 \%$ of patients with NCCP. $^{33}$ Endoscopy is therefore not recommended as the routine firstline investigation for NCCP unless there are concomitant symptoms suggestive of oesophageal pathology. About 29-49\% of Asian patients with NCCP have abnormal oesophageal acid exposure as measured by $\mathrm{pH}$ monitoring. ${ }^{34-37}$

Ambulatory $\mathrm{pH}$ monitoring allows quantitative assessment of acid exposure and determination of the chronological relationship between reflux and chest pain episodes, and is positive in $29 \%$ of patients. ${ }^{37}$ As NCCP tends to occur in an episodic manner and 24-hour monitoring may not capture every pain episode, wireless $\mathrm{pH}$ monitoring that allows prolonged $\mathrm{pH}$ monitoring for up to 96 hours could increase the diagnostic yield. ${ }^{38}$ The application of routine $\mathrm{pH}$ monitoring is limited in Asia as it is not readily available. A therapeutic trial of PPI for patients with NCCP remains the most practical approach in primary care. Patients with failed therapy could be investigated for PPI-refractory GORD symptoms (see Statement 15). A meta-analysis in 2005 reported overall sensitivity and specificity of $80 \%$ (95\% CI $71 \%$ to $87 \%)$ and $74 \%(95 \% \mathrm{CI}$ $64 \%$ to $83 \%$ ), respectively, in a Western population. ${ }^{39}$ The duration of PPI therapy for GORD-related NCCP has yet to be defined. ${ }^{40}$

CQ8. Should a diagnosis of reflux laryngitis be made solely on laryngoscopic findings?

Statement 8

Laryngoscopic findings are unreliable for the diagnosis of laryngopharyngeal reflux (LPR) and should not be used for diagnosis. 
Agreement: $100 \%$

Quality of evidence: Moderate

Strength of recommendation: Strong

A number of laryngoscopic findings have been implicated as specific features for LPR. These findings include reflux granuloma, vocal cord oedema, posterior commissure hypertrophy, ventricular obliteration and pseudosulcus. ${ }^{41}$ Among these signs, Reinke's oedema has been associated with abnormal oesophageal $\mathrm{pH}$ monitoring in patients with symptoms of LPR in a Korean study. ${ }^{42}$ A scoring system based on these laryngeal signs has been developed to facilitate the diagnosis of LPR. However, both the sensitivity and specificity of this laryngoscopic scoring system is $<50 \%$. Furthermore, the definition of these laryngeal signs is subject to substantial intra- and inter-observer variability. On the other hand, it has been reported that the presence of ERD detected by endoscopy is predictive of a good treatment response of LPR symptoms to PPI treatment. ${ }^{43}$

CQ9. What is the role of reflux monitoring in patients with extra-oesophageal presentation of GORD?

\section{Statement 9}

Reflux monitoring has a limited role for the diagnosis of extraoesophageal GORD in Asia and it is not recommended as routine investigation.

Agreement: $79 \%$

Quality of evidence: Moderate

Strength of recommendation: NA

Reflux monitoring, in the form of either $\mathrm{pH}$ or combined $\mathrm{pH}$-impedance monitoring, allows quantitative assessment of gastric refluxate exposure in the pharynx and oesophagus. For the diagnostic investigation of extra-oesophageal presentation, dual-channel (pharynx and $5 \mathrm{~cm}$ above the lower oesophageal sphincter) or multichannel (pharynx, proximal oesophagus, $5 \mathrm{~cm}$ above lower oesophageal sphincter) monitoring has been proposed. A newly developed pharyngeal $\mathrm{pH}$ monitoring has reported higher sensitivity. ${ }^{44}$ Reflux monitoring can be further coupled with intraluminal pressure sensor monitoring to detect cough episodes in order to determine the chronological relationship between reflux and suspected extra-oesophageal symptoms.

However, reflux monitoring as a diagnostic tool for extraoesophageal GORD is associated with many shortcomings. First, there is a lack of an objective and standardised method for evaluating correlation between reflux and extra-oesophageal syndromes like asthma or laryngitis. The application of automated analysis and interpretation using commercially available software to replace manual analysis which is time consuming and subject to substantial inter- or intra-observer variability is limited by artefacts such as swallowing and cough. ${ }^{45}$ Second, there is a lack of a universally accepted normal range of proximal oesophagus and pharyngeal acid exposure for the Asian population. Third, it has been reported that reflux monitoring has low sensitivity and specificity for the diagnosis of extra-oesophageal GORD manifestations. ${ }^{44}$ The predictive value of reflux monitoring for a positive PPI symptom response is also poor. A therapeutic trial of PPI remains a pragmatic approach in the context of limited access or expertise of reflux monitoring in Asia. In one Asian study the efficacy of PPI was primarily limited to those patients with concomitant typical reflux symptoms or oesophagitis. ${ }^{46}$

\section{Refractory GORD}

CQ10. What is the definition of refractory GORD in Asia?

Statement 10

In the Asia-Pacific region, persistent and troublesome GORD symptoms unresponsive to at least 8 weeks of a standard dose of PPI may be termed refractory GORD symptoms.
Agreement: 100\%

Quality of evidence: NA

Strength of recommendation: NA

There is no consensus on the definition of refractory GORD in Asia or in the Western world. The term 'refractory GORD' is reserved for patients whose symptoms fail to respond partially or completely to a standard dose of PPI after a sufficient period of therapy. In the Asian context, the standard dose of PPI is defined as the approved dose in each country or region and the period of therapy as 8 weeks. As GORD symptoms respond well to PPI, PPI-refractory GORD refers to patients with symptoms of GORD who do not respond or only partially respond to therapy. Troublesome symptoms refer to impairment of quality of life (QOL). This group is a subset of patients with GORD symptoms, many of whom may not have GORD at all. In the rest of this paper we shall refer to the actual group as having refractory GORD symptoms.

\section{CQ11. What is the prevalence of refractory GORD symptoms in}

Asia?

Statement 11

PPI-refractory GORD symptoms are common and more prevalent in patients with NERD.

Agreement: 100\%

Quality of evidence: Moderate

Strength of recommendation: NA

The reported rates of PPI-refractory GORD vary among studies. This is likely due to differing definitions of failure, patient selection and the variation of PPI dose. A systematic literature review was conducted to identify and characterise the proportion of adults with GORD who experience partial or non-response of their reflux symptoms to PPI therapy, both in primary care and in community-based studies. Nineteen studies in individuals with GORD taking a PPI were included. These studies were from North America, Europe and Australia. In interventional non-randomised primary care trials, the prevalence of persistent troublesome heartburn and regurgitation was $17 \%$ and $28 \%$, respectively; in randomised trials it was $32 \%$ and $28 \%$, respectively. In observational primary care and community-based studies, $45 \%$ of participants reported persistent GORD symptoms. Overall, persistent GORD symptoms despite PPI treatment were more likely in studies with a higher proportion of female participants but less likely in studies from Europe than in those from the USA, and were associated with decreased psychological and physical well-being. ${ }^{47}$ Data from Asia are more limited. A study from China showed that the prevalence of PPI-refractory GORD symptoms was $37.9 \%$ in patients with NERD after a standard dose of PPI therapy for 6 months. ${ }^{48}$ In Korea, PPI-refractory GORD symptoms occurred in $16.7 \%$ of patients with NERD and $6.6 \%$ of those with ERD after 8 weeks of PPI treatment. ${ }^{49}$ In Japan, after 4 weeks of PPI therapy, more patients with ERD than with NERD reported complete symptom resolution $(55.4 \%$ vs $35.8 \%) .{ }^{50}$ In comparison, a post hoc analysis of four randomised controlled trials (RCTs) showed that between $14 \%$ and $19 \%$ of patients with GORD partially responded to PPI therapy. This was higher in patients with NERD (19.9\%) than in those with ERD (14\%). Non-response to PPI was rare (NERD 2.4\%, ERD 1.4\%) in the analyses. 51

CQ12. Do refractory GORD symptoms affect patients' QOL? Statement 12

Refractory GORD symptoms affect patients' QOL including sleep and work. 
Agreement: $100 \%$

Quality of evidence: Moderate

Strength of recommendation: NA

A systematic review showed that patients with refractory GORD symptoms have reduced physical and mental health-related QOL by $8-16 \%$ and $2-12 \%$, respectively. ${ }^{52}$ Compared with individuals with non-disruptive GORD, those with disruptive GORD had 2.4 times and 1.5 times higher mean rates of absenteeism and presenteeism, respectively. ${ }^{53}$ The major impact on QOL in patients with refractory GORD is sleep disturbance. Sleep disturbance is more prevalent in patients with ERD or NERD than in non-GORD individuals. ${ }^{54} 55$ Sleep disturbance can result in emotional stress and decreased work performance. ${ }^{55}{ }^{56}$ Improving the control of GORD symptoms can improve QOL in patients.

\section{CQ13. What are the causes of refractory GORD symptoms? Statement 13}

The main causes of refractory GORD symptoms include: (1) insufficient inhibition of gastric acid secretion; (2) ongoing weakly acidic (or non-acid) reflux; (3) non-GORD causes; (4) reflux sensitivity.

Agreement: 94.7\%

Quality of evidence: Moderate

Strength of recommendation: NA

It is recognised that there is not a single cause for symptoms refractory to PPI treatment. Causes include reflux and non-reflux-related aetiologies. Reflux-related causes refer to ongoing acidic and non-acidic reflux. Non-reflux causes include dysmotility, eosinophilic oesophagitis, functional heartburn, overlap syndrome with IBS and visceral hypersensitivity (table 1).

Using 24-hour $\mathrm{pH}$ studies, pathological reflux can be found in a substantial proportion of patients (ie, 25\%) with refractory GORD symptoms. ${ }^{57-59}$ In addition, combined impedance-pH studies have been able to identify non-acid reflux-related symptom episodes in other patients with PPI-refractory GORD. ${ }^{60}$ Impaired responses to PPI might be related to a number of factors including increased body weight ${ }^{61}$ or genotypes of the P450 system that influence PPI metabolism. ${ }^{62} 63$

There is evidence that psychological factors may be related to the manifestation of symptoms in the absence of acidic reflux. In a well-controlled study in patients with recurrent GORD symptoms after antireflux surgery, patients with recurrent

Table 1 Diagnostic possibilities for refractory reflux symptoms

\begin{tabular}{ll}
\hline Non-GORD & Delayed gastric emptying (common) \\
& Motility disorder: achalasia (common) \\
& Functional (common): normal reflux burden, no \\
& symptom/reflux correlation \\
& Aerophagia (less common) \\
& Rumination (less common) \\
& Eosinophilic oesophagitis (if dysphagia is present) \\
Weakly acidicl & May occur after acid suppression in context of \\
non-acidic reflux & regurgitation due to mechanical failure (large hiatal \\
& hernia) \\
Insufficient acidic & Dosing (common) \\
suppression & Compliance (common) \\
& Zollinger-Ellison syndrome (rare) \\
& PPI resistance (less common) \\
Reflux sensitivity & Reflux burden is normal but patient has a clear \\
& symptom/reflux correlation. This is dependent on \\
& visceral hypersensitivity and hypervigilance \\
\hline
\end{tabular}

PPI, proton pump inhibitor. symptoms but without acidic reflux during 24-hour $\mathrm{pH}$ studies had significantly more psychiatric comorbidities such as depression than patients with pathological reflux during a 24-hour $\mathrm{pH}$ study. ${ }^{64}$

Patients with NERD are less likely to respond to antisecretory therapy. ${ }^{61}$ Some of these patients have visceral hyperalgesia to acid and also to saline perfusion. ${ }^{65}{ }^{66}$ This suggests that, in patients not responding to routine acid suppression, oesophageal hypersensitivity may play a role in symptom manifestation.

\section{CQ14. Is eosinophilic oesophagitis a cause of refractory GORD in}

Asia?

\section{Statement 14}

Eosinophilic oesophagitis is an uncommon cause of refractory GORD symptoms in Asia.

Agreement: $100 \%$

Quality of evidence: Low

Strength of recommendation: NA

Eosinophilic oesophagitis is increasingly diagnosed in patients with oesophageal symptoms, especially dysphagia and GORD-like symptoms. ${ }^{67} 68$ The estimated prevalence of eosinophilic oesophagitis based on a multicentre study in Japan was $17.1 / 100000^{69}$ persons compared with $56.7 / 100000^{70}$ persons in the USA. A single-centre study from Japan yielded a prevalence of $0.08 \% .{ }^{71}$ Two other studies from Japan demonstrated higher prevalence rates of $2.5 \%$ and $0.13 \% .{ }^{72} 73$ The prevalence rates based on other studies from China and Korea range from $0.34 \%{ }^{74}$ to $6.6 \%,{ }^{75}$ depending on whether it was communitybased or endoscopy unit-based data. Patients with eosinophilic oesophagitis may respond to PPI. A multicentre study showed a prevalence of $0.01 \%$ for eosinophilic oesophagitis and $0.02 \%$ for PPI-responsive eosinophilic oesophageal infiltration. ${ }^{71}$ Eosinophilic oesophagitis accounted for $0.9 \%$ of PPI treatment failure in patients in a US study. ${ }^{76}$

\section{CQ15. What investigations are available for investigation of} refractory GORD?

Statement 15

After ascertaining medication compliance, further investigations available to better categorise underlying pathophysiology and target therapy include upper GI endoscopy \pm enhanced imaging and function testing (ie, ambulatory $\mathrm{pH}$ monitoring and 24-hour combined impedance-pH studies/oesophageal manometry).

Agreement: $100 \%$

Quality of evidence: Moderate

Strength of recommendation: Strong

Non-responders to PPI may be considered for referral for evaluation. Investigations in patients with refractory GORD aim to better categorise the underlying pathophysiology and target a suitable therapy. Before proceeding with investigations, symptom reassessment should be done to determine whether the persistent symptoms may be attributable to gastrooesophageal reflux. Detailed history-taking may suggest achalasia, rumination or belching syndrome rather than reflux. Compliance and optimal PPI dosing should be determined before proceeding to endoscopy or function testing. Endoscopy is recommended for all patients with GORD symptoms that are persistent or progressive despite appropriate medical therapy. Endoscopy may detect hiatal hernia, reflux oesophagitis and its complications, such as peptic stricture and BO. Narrow band imaging (NBI) endoscopy enhances mucosal morphology at the squamocolumnar junction. NBI may aid white light endoscopy (WLE) and increase the sensitivity of endoscopy for the 
diagnosis of GORD. ${ }^{77} 78$ Endoscopy may identify non-GORD aetiologies such as eosinophilic oesophagitis, infection and pill injury, and suggest achalasia. ${ }^{71} 7479$ In patients with negative endoscopy (which is the most common result), ambulatory reflux monitoring $(\mathrm{pH}$ or impedance- $\mathrm{pH}$ ) is recommended to quantify reflux and assess the relationship between reflux episodes and the patient's symptoms if resources are available. $^{59} \quad 60 \quad 80$ An alternative would be an alternate PPI of double-dose PPI. Telemetry capsule allows prolonged 48-hour monitoring with improved patient tolerance and provides a higher chance of finding a positive symptom association than 24-hour transnasal catheter recording. ${ }^{81} \mathrm{pH}$ monitoring is ideally performed with the patient 'off' acid inhibitors. Combined $\mathrm{pH}$-impedance monitoring can detect all types of reflux, including acid and weakly acidic, liquid and gaseous. It is best performed with the patient 'off' PPI therapy when the diagnosis of GORD is in doubt and for evaluation before considering surgery in a patient with NERD. ${ }^{82}$ Measurement with the patient 'on' PPI treatment is useful when reflux is likely and the main question is why the treatment is ineffective. ${ }^{83} 84$ Oesophageal manometry has some role in diagnosing refractory GORD. It is used to rule out achalasia or severe hypomotility and should be done prior to any consideration of surgery. It is also used to help in the placement of transnasal $\mathrm{pH}$-impedance probes.

\section{CQ16. What medications are available to treat PPI-refractory GORD symptoms?}

Statement 16

PPI remain the cornerstone for treatment of patients with persistent symptoms. Increasing the dose or switching to another PPI can benefit a subset of patients. Histamine-2 receptor antagonists (H2RA), alginates, in addition to PPI, improve control of GORD symptoms in some patients.

Agreement: 100\%

Quality of evidence: Moderate

Strength of recommendation: Strong

Non-compliance and suboptimal dosing are common causes of PPI failure. ${ }^{85} 86$ RCTs have shown that switching to another PPI was effective in symptom relief in some patients with refractory GORD symptoms and may be cost effective. ${ }^{87} 88 \mathrm{~A}$ meta-analysis demonstrated a modest $5 \%$ relative increase in the probability of healed ERD with esomeprazole compared with other PPI (lansoprazole, omeprazole, pantoprazole) at 8 weeks. ${ }^{89}$ Another meta-analysis showed no difference in relief of symptoms with omeprazole $20 \mathrm{mg}$, lansoprazole, pantoprazole $40 \mathrm{mg}$ and rabeprazole $20 \mathrm{mg}$. Esomeprazole at $40 \mathrm{mg}$ provided better symptom relief compared with omeprazole $20 \mathrm{mg}$, but not with the other PPI. ${ }^{90}$ Polymorphism of CYP2C19 results in extensive metabolisers, poor metabolisers or intermediate metabolisers of PPI. Systematic exposure to PPI is 5-12 times higher in poor metabolisers than in extensive metabolisers. ${ }^{91}$ Extensive metabolisers were associated with higher rates of symptomatic recurrence of GORD. ${ }^{63}$ The influence of CYP2C19 polymorphism differs between PPI. At a standard dose of lansoprazole, omeprazole and rabeprazole the 24-hour median $\mathrm{pH}$ in extensive metabolisers was least affected with the use of rabeprazole. ${ }^{92}$ A randomised crossover study showed that, in intermediate and poor metabolisers, PPI twice daily could attain sufficient acid suppression with all PPI (esomprazole $20 \mathrm{mg}$, omeprazole $20 \mathrm{mg}$, lansoprazole $30 \mathrm{mg}$, rabeprazole $10 \mathrm{mg}$ ). In extensive metabolisers, esomeprazole twice daily had the strongest inhibition. ${ }^{93}$ Dexlansoprazole, the enteric coated R-enantiomer of lansoprazole, contains two different sets of enteric coated capsules that disintegrate in different parts of the GI tract resulting in dual release with two peaks of plasma concentration. In addition to demonstrating efficacy over placebo in patients with NERD, ${ }^{94}$ dexlansoprazole was superior to lansoprazole in healing of ERD, particularly in moderate to severe disease. $^{95}$ Dexlansoprazole allows flexible dosing such that administration of the drug could be independent of timing of food intake. ${ }^{96}$ The administration of pantoprazole and rabeprazole is also unaffected by timing of food intake. ${ }^{96} 97$ The choice of PPI in patients with refractory symptoms may be partly influenced by these pharmacokinetic considerations but ultimately the decision is made by the physician and patient, taking into consideration cost, availability, clinical response and dosing convenience. Switching to another PPI, increasing to twice daily dosing or doubling a single dose have been shown to result in symptomatic relief in about $20-26 \%$ of patients. ${ }^{87}$

In Asia, available prokinetics include mosapride, itopride and domperidone. Overall, their effect is modest. A systematic review that compared the efficacy of mosapride plus PPI with PPI monotherapy in GORD did not show any benefit. ${ }^{98}$ The addition of mosapride to PPI was shown to improve symptoms in patients with GORD with dysmotility symptoms. ${ }^{99-101}$ Itopride combined with lansoprazole has been shown to significantly improve reflux and globus symptoms in patients with LPR compared with lansoprazole. ${ }^{102}$

A Cochrane analysis showed that additional H2RA at bedtime might decrease nocturnal gastric acid breakthrough. ${ }^{103}$ The authors stopped short of recommending H2RA use at bedtime in view of tachyphylaxis occurring on long-term therapy. ${ }^{104}$ H2RA can be used on a short-term intermittent basis to overcome nocturnal reflux.

In a small study conducted on a group of patients with symptomatic GORD with large hiatal hernias using scintigraphy, manometry and $\mathrm{pH}$-impedance monitoring, it was demonstrated that alginate-antacid raft localised the postprandial acid pocket and displaced it below the diaphragm, reducing postprandial acid reflux. ${ }^{105}$ A RCT showed that adding sodium alginate to PPI resulted in a significantly greater rate of complete resolution of heartburn in patients with NERD. ${ }^{106}$

Baclofen, a GABA agonist, decreases the 24-hour $\mathrm{pH}$ score, percentage of upright reflux episodes, number of acid exposures and percentage of time with $\mathrm{pH}<4 .{ }^{107}$ It is useful as an add-on therapy to PPI but is limited by side effects that include somnolence, dizziness, weakness and trembling.

\section{CQ17. Is surgery a therapeutic option in patients with refractory} GORD symptoms?

\section{Statement 17}

Surgery in experienced hands is a treatment option for patients with refractory GORD symptoms failing medical therapy and recommended only in those with objectively documented gastro-oesophageal reflux.

Agreement: 100\%

Quality of evidence: Moderate

Strength of recommendation: Strong

A Cochrane systemic review comparing medical management with laparoscopic fundoplication surgery showed that there were statistically significant improvements in health-related QOL at 3 months and 1 year following surgery compared with medical therapy. ${ }^{108}$ Surgery is, however, not without risks. Postoperative dysphagia and gas bloat syndrome may also occur. The LOTUS RCT comparing laparoscopic antireflux surgery versus esomeprazole treatment in patients with established GORD showed that at 5 years the remission rate was higher in 
the medication group than the surgical group $(92 \%$ vs $85 \%$, $\mathrm{p}=0.048) .{ }^{109}$ The difference was no longer significant following best case scenario modelling of study dropouts.

Frazzoni et al specifically looked at the impact of laparoscopic fundoplication on patients with PPI-refractory reflux symptoms. ${ }^{110}$ A pH-impedance study was used to confirm the diagnosis of GORD prior to surgery. Preoperative on-PPI impedance- $\mathrm{pH}$ diagnostic criteria consisted of positive symptom association probability (SAP)/symptom index (SI) and/or abnormal percentage oesophageal acid exposure time (\%EAET) and/or abnormal number of total refluxes. GORD cure was defined by 3-year postoperative off-PPI normal impedance-pH findings with persistent symptom remission. Preoperatively, 24/38 (63\%) patients who completed the outcome assessment had a positive SAP/SI, 20/38 (53\%) for weakly acidic refluxes; $3 / 38$ (8\%) patients had an abnormal \%EAET and $11 / 38$ (29\%) had an abnormal number of total refluxes only. Postoperatively, heartburn/regurgitation recurred in three patients; abnormal impedance-pH findings were found in two of them and they responded to PPI therapy. GORD cure was achieved in 34/38 $(89 \%)$ patients and in 11/11 patients with an abnormal number of total refluxes as the only preoperative abnormal impedance-pH finding. Postoperatively, there was a significant decrease in the $\%$ EAET ( $1 \%$ vs $0.1 \%, p=0.002)$ and in the number of total refluxes (68 vs $8, p=0.001$ ), with the latter finding mainly due to a decrease in the number of weakly acidic refluxes. Data on the clinical outcomes of surgery in Asia are lacking.

\section{CQ18. What is the treatment of functional heartburn? \\ Statement 18}

Antidepressants such as tricyclic antidepressants and selective serotonin reuptake inhibitors have been used to treat functional heartburn but the response is variable.

Agreement: $100 \%$

Grade of evidence: Low

Strength of recommendation: Weak

Patients with normal manometry, normal oesophageal acid exposure and a negative symptom association after oesophageal function tests can be classified as having functional heartburn. Their symptom response to PPI is usually poor. ${ }^{111}$ The underlying pathophysiology is poorly understood but postulated aetiologies include oesophageal hypersensitivity from altered pain perception, subtle oesophageal motor abnormalities and psychological factors.

As altered oesophageal/visceral pain perception is postulated to be the main pathophysiology of functional heartburn, low dose pain modulators such as tricyclic antidepressants and selective serotonin reuptake inhibitors can be used. Data on their efficacy have been shown in hypersensitive oesophagus. ${ }^{112} 113$ Although no RCT has shown benefits of cognitive behavioural therapy, it may be useful for those with underlying psychosomatic disorders. Relaxation training in a small number of patients with GORD has been shown to reduce symptom scores and oesophageal acid exposure. ${ }^{114}$ Abdominal breathing exercise has been reported to improve the QOL score in patients with GORD. ${ }^{115}$ As some patients with functional heartburn exhibit oesophageal hypersensitivity, therapies used for functional chest pain such as hypnotherapy may have therapeutic effects. ${ }^{116} 117$

CQ19. Is there a role for lifestyle modification in the treatment of refractory GORD?

Statement 19

Weight reduction in those who are overweight or obese can improve symptom control, although data on the long-term effect are limited.
Agreement: $100 \%$

Quality of evidence: Moderate

Strength of recommendation: Strong

A systematic review of 16 clinical studies in 2006 evaluated the effects of various lifestyle changes on GORD symptoms. ${ }^{118}$ The study concluded that weight loss and bed elevation are effective lifestyle interventions for GORD. The HUNT study, a prospective population-based cohort study from Norway, showed a dose-dependent association between weight loss and reduction of GORD symptoms and increased treatment success with antireflux medication. Among individuals with $>3.5$ units decrease in BMI, the OR of loss of any reflux symptoms (minor or severe) was 1.98 (95\% CI 1.45 to 2.72) when using no or less than weekly antireflux medication and 3.95 (95\% CI 2.03 to 7.65 ) when using at least weekly antireflux medication. ${ }^{119}$

CQ20. Should patients with persistent extra-oesophageal symptoms despite PPI therapy be investigated for non-GORD aetiologies prior to endoscopy or ambulatory $\mathrm{pH}$ testing? Statement 20

Patients with presumed extra-oesophageal symptoms and who failed PPI therapy should be investigated for non-GORD causes before proceeding to endoscopy or function testing.

Agreement: $94.7 \%$

Quality of evidence: Low

Strength of recommendation: Strong

Extra-oesophageal symptoms such as hoarseness, throat pain, asthma and cough are the least likely to be resolved with PPI treatment, in part because they are often not caused by reflux. ${ }^{120-122}$ GORD can be viewed as a possible contributing factor in some, but not all, patients presenting with extraoesophageal symptoms. ${ }^{11}$ All patients with presumed extraoesophageal symptoms and who have failed PPI therapy should have careful diagnostic evaluation for non-GORD causes before the commencement of GI evaluation. Non-GORD aetiologies should be ruled out through pulmonary, otolaryngology and allergy evaluations.

\section{Algorithm for the management of refractory GORD symptoms}

The management of patients with refractory GORD symptoms despite PPI therapy is complex as the population with these symptoms is heterogeneous. The first distinction is whether the patient has GORD that is truly refractory to PPI or non-GORD pathology. Defining the clinical phenotype requires the judicious contribution of endoscopy combined with reflux testing and oesophageal manometry. Facilities for endoscopy in Asia are available, but facilities and experience with functional testing are more limited. Furthermore, patients in areas with available functional testing may choose empirical therapy to alleviate their symptoms. This approach is practical, but functional testing is required prior to antireflux surgery. The management algorithm for regions with limited access to functional testing is summarised in figure 1. For patients who are agreeable to functional testing or in areas where these facilities are readily available, the algorithm is shown in figure 2 .

\section{Barrett's oesophagus (B0)}

CQ21. What are the diagnostic criteria for the diagnosis of BO? Statement 21

The diagnostic criterion for $\mathrm{BO}$ is replacement of the normal distal squamous epithelial lining by columnar epithelium. This must be clearly visible endoscopically $(\geq 1 \mathrm{~cm}$ above the gastrooesophageal junction) and be confirmed by histology. 
Figure 1 Management algorithm in regions with limited access to functional testing. GERD; gastro-oesophageal reflux disease; H2RA, histamine-2 receptor antagonist; PPI, proton pump inhibitor;

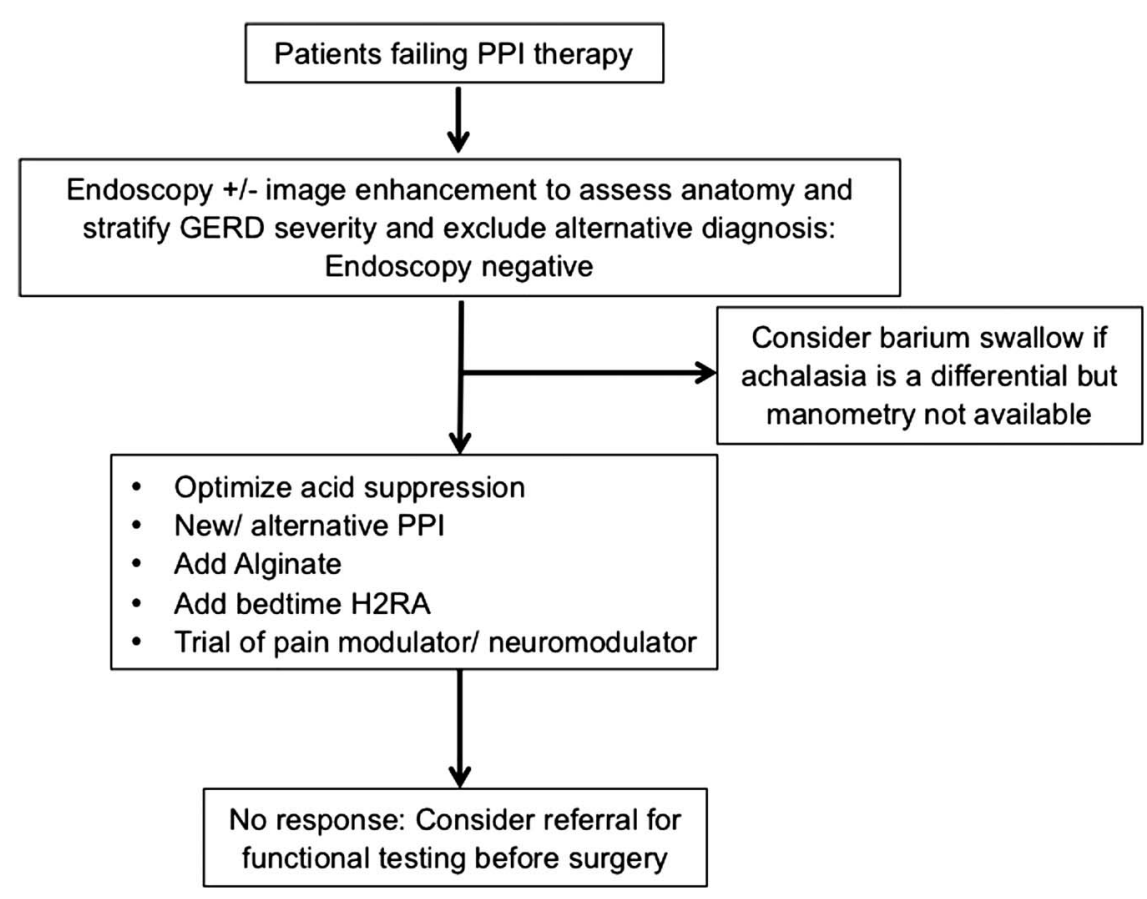

Agreement: 79\%

Quality of evidence: Moderate

Strength of recommendation: Strong

Differences in the definition of $\mathrm{BO}$ could potentially influence the frequency of diagnosis of BO at index endoscopy. For comparability of diagnoses and endoscopic measures of outcomes following treatment, an internationally accepted set of criteria is important. For the definitive diagnosis of BO, the endoscopic finding of columnar lined oesophagus in the distal oesophagus must be corroborated with histological evidence of columnar epithelium. Whether the additional presence of IM is a diagnostic prerequisite is controversial. ${ }^{5}{ }^{123-125}$ The American College of Gastroenterology (ACG) 2011 guidelines required the presence of IM for the diagnosis of BO. ${ }^{123}$ The rationale for requiring IM is based on its greater risk for progression to carcinoma in early pathological ${ }^{126} 127$ and population studies. ${ }^{128}$ On the other hand, the British ${ }^{5}$ and Japanese ${ }^{129}$ guidelines do not require IM for the diagnosis of $\mathrm{BO}$. In the previous Asia-Pacific consensus ${ }^{4}$ the presence of IM was required for the diagnosis of BO. In this consensus, the definition of BO was redefined due to the following considerations. First, if IM was required as a diagnostic criterion, mucosal biopsy sampling bias may confound diagnosis. A study that examined the diagnostic yield of IM in patients with known BO found that the optimum number of biopsies to diagnose IM was eight, with a yield of $67.9 \%$. In contrast, if only four were taken, the yield of IM was $34.7 \%$. There was no increased yield with more than eight biopsies, unless more than 16 biopsies were taken (100\% yield of IM). ${ }^{130}$ Second, two retrospective studies suggested that non-goblet columnar metaplasia of the distal oesophagus had a similar neoplastic potential to IM. ${ }^{131} 132$

Columnar lined oesophagus length of $1 \mathrm{~cm}$ (M of Prague criteria $^{133}$ was chosen by the British guidelines to be the minimum length for an endoscopic diagnosis of $\mathrm{BO}$ in order to distinguish it from an irregular Z-line. ${ }^{5}$ Indeed, the Asian Barrett's Consortium showed there was an excellent interobserver agreement in the endoscopic diagnosis and grading of $\mathrm{BO}$ using the Prague C \& $\mathrm{M}$ criteria for Barrett's segment of $>1 \mathrm{~cm}$. For those segments $<1 \mathrm{~cm}$, the interobserver reliability in diagnosis was low. ${ }^{134}$ The revised definition would exclude all ultrashort segment BO (USSBO), leaving only short segment BO (SSBO) $(1-<3 \mathrm{~cm})$ and long segment BO (LSBO) $(>3 \mathrm{~cm})$ for consideration. It would exclude gastro-oesophageal junction changes from the definition of $\mathrm{BO}$.

CQ22. What is the prevalence of BO in the Asia-Pacific region in the last 6 years?

\section{Statement 22} low and the most common type is short segment.

Agreement: 100\%

Quality of evidence: Moderate

Strength of recommendation: NA

The prevalence of $\mathrm{BO}$ in most parts of the Asia-Pacific region is low and the data, which are based on endoscopic series, are summarised in table $2 .^{135-144}$ One important point to note is the high prevalence rates reported from Japan. This discrepancy is due to definitions used and the entity of USSBO in Japan, where the length is $<1 \mathrm{~cm}$. Endoscopists are unable to endoscopically recognise or reliably measure very short lengths $(<1 \mathrm{~cm})$ of $\mathrm{BO}$ because the precise gastro-oesophageal junction can be difficult to identify, particularly in the presence of a hiatus hernia, and measurement and precise identification of the site of biopsy in relation to the gastro-oesophageal junction may be difficult due to peristalsis. Therefore, there are concerns about the accuracy of the diagnosis of USSBO. Outside Japan the data for $\mathrm{BO}$ prevalence rates refer to segments longer than $1 \mathrm{~cm} .{ }^{5}$ If USSBO is excluded, the prevalence rates from Japan are actually similar to other Asian countries. For instance, recent papers by Okita et $a l^{139}$ and Watari et $a l^{140}$ reported overall $\mathrm{BO}$ prevalence rates of $37.6 \%$ and $36.4 \%$, respectively. However, in the paper by Okita et al, SSBO occurred in $37.4 \%$ and LSBO in $0.2 \%$. Among the cases of SSBO, the mean length was $0.77 \pm 0.43 \mathrm{~cm}$, suggesting that the majority were in fact USSBO. ${ }^{139}$ In the paper by Watari et al, after exclusion of USSBO, the $\mathrm{BO}$ prevalence rate was 5.6\% (SSBO: 5.4\%; LSBO: $0.2 \%) .{ }^{140}$
The prevalence of $\mathrm{BO}$ in most parts of the Asia-Pacific region is 


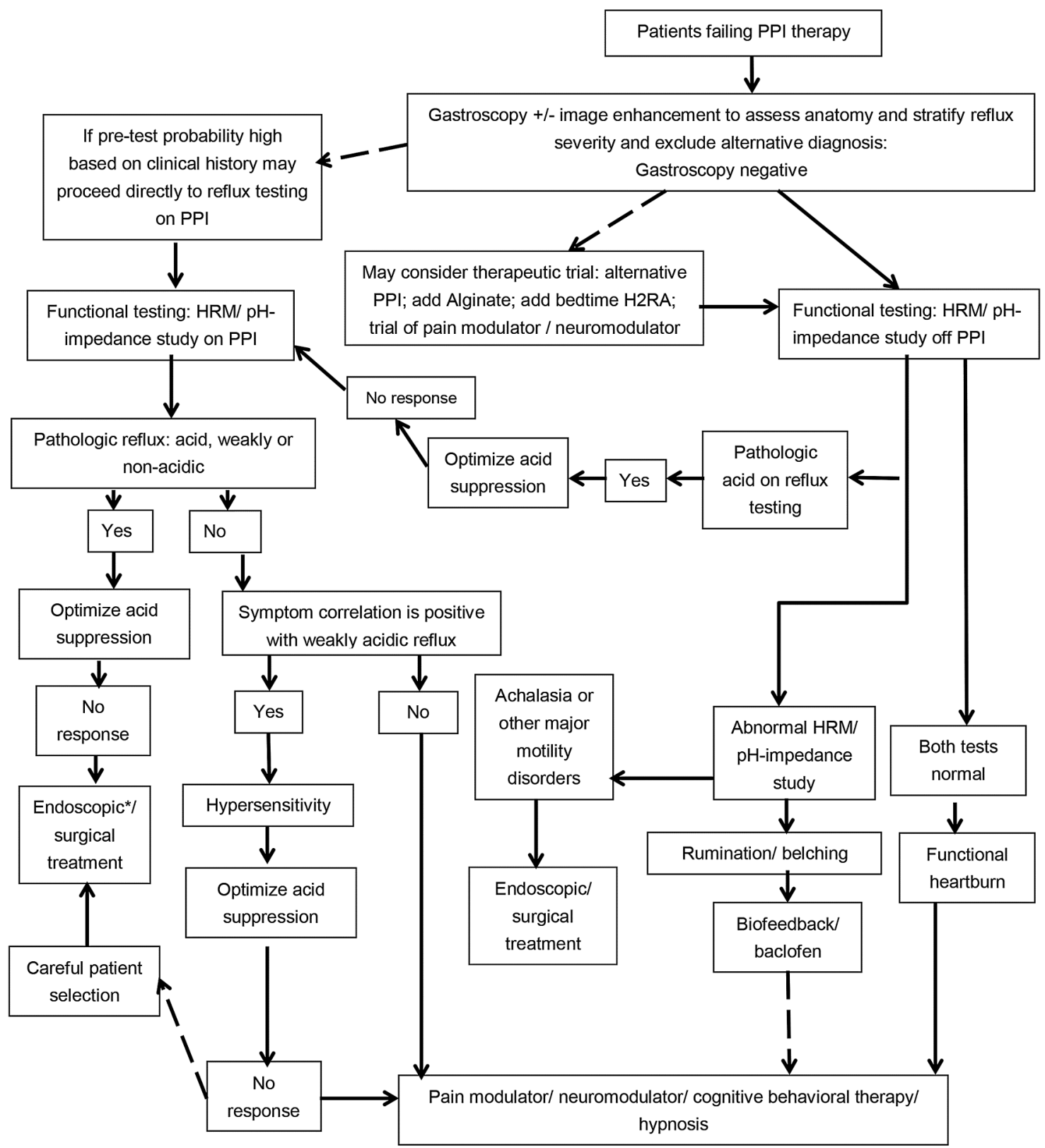

H2RA: histamine 2 receptor antagonist; HRM: high-resolution manometry; PPI: proton pump inhibitor

${ }^{*}$ Endoscopic therapies are options based on approval and device availability

Figure 2 Management algorithm in regions with access to functional testing.

\section{CQ23. What are the risk factors for BO in Asia?}

\section{Statement 23}

The risk factors for BO in the Asia-Pacific region are ethnicity, older age and male gender, long duration of reflux symptoms, abdominal obesity and smoking.

Agreement: 94.7\%

Quality of evidence: Moderate

Strength of recommendation: NA

Ethnicity is a risk factor for BO. Caucasians have a higher risk than Asians for BO. ${ }^{146-148}$ Corley et al ${ }^{146}$ reviewed communitybased data captured electronically and reported an annual incidence rate of 39/100 000 among non-Hispanic whites compared with 16/100 000 among Asians. Lam et al performed a crosssectional study to determine the proportion of $\mathrm{BO}$ from all consecutive patients who underwent endoscopy. BO was significantly more common in non-Asian Americans than in Asians $(2.1 \%$ vs $0.76 \%$ ), and non-Asian ethnicity was associated with an OR of 3.55 (95\% CI 1.85 to 6.85 ) for the presence of $\mathrm{BO}^{147}$ Ford et al reported that $\mathrm{BO}$ was more common in white Caucasians than in South Asians (2.8\% vs $0.3 \%$; OR $6.03,95 \%$ CI 3.56 to 10.22$).{ }^{148}$ Rajendra et $a l^{149}$ reported that within Malaysia, a multi-ethnic Asian country, BO was significantly more common in Indians than in Chinese and Malays. Similar to the Western world, older age, male gender and long duration of reflux symptoms have been associated with BO. ${ }^{136} 138141145150$ In a multicentre prospective Korean study, male gender (OR 1.82; 95\% CI 1.32 to 2.50) and older age (>60 vs < 40 years) (OR $1.81 ; 95 \%$ CI 1.07 to 3.09 ) were significant risk factors. ${ }^{141}$ In a prospective study from Taiwan, Kuo et $a l^{150}$ reported that GORD duration longer than 5 years (OR 4.2; 95\% CI 1.2 to 4.8) was an independent risk 
Table 2 Prevalence rates of Barrett's oesophagus (BO) in Asia

\begin{tabular}{|c|c|c|c|}
\hline Country & Reference & Study population & Prevalence rate \\
\hline Australia & Kendall and Whiteman ${ }^{135}$ & $\begin{array}{l}\text { Unselected patients undergoing endoscopy } \\
(\mathrm{N}=2593)\end{array}$ & $1.89 \%$ \\
\hline China & Xiong et $a l^{136}$ & $\begin{array}{l}\text { Unselected patients undergoing endoscopy } \\
(\mathrm{N}=2022)\end{array}$ & $1 \%$ \\
\hline \multirow[t]{2}{*}{ India } & Dhawan et al ${ }^{137}$ & $\begin{array}{l}\text { Unselected patients undergoing endoscopy } \\
(\mathrm{N}=271)\end{array}$ & $6 \%$ \\
\hline & Mathew et $a l^{138}$ & Patients with reflux disease $(\mathrm{N}=278)$ & 9\% had CLO with IM; $16.54 \%$ had CLO \\
\hline \multirow[t]{2}{*}{ Japan } & Okita et $a^{139}$ & $\begin{array}{l}\text { Unselected patients undergoing endoscopy } \\
(\mathrm{N}=5338)\end{array}$ & $\begin{array}{l}\text { Overall: } 37.6 \% \\
\text { SSBO (mean length } 0.77 \pm 0.43 \mathrm{~cm} \text { ): } 37.4 \% \\
\text { LSBO: } 0.2 \%\end{array}$ \\
\hline & Watari et al ${ }^{140}$ & $\begin{array}{l}\text { Unselected patients undergoing endoscopy } \\
(\mathrm{N}=1581)\end{array}$ & $\begin{array}{l}\text { SSBO: } 5.4 \% \\
\text { LSBO: } 0.2 \% \\
\text { (Ultrashort: } 30.8 \% \text { ) }\end{array}$ \\
\hline Korea & Park et $a l^{141}$ & $\begin{array}{l}\text { Multicentre Korean study of patients undergoing endoscopy } \\
(\mathrm{N}=25536)\end{array}$ & $0.84 \%$ \\
\hline Malaysia & Rosaida and Goh ${ }^{142}$ & $\begin{array}{l}\text { Unselected patients undergoing endoscopy } \\
(\mathrm{N}=1000)\end{array}$ & $2 \%$ \\
\hline Singapore & Ang et $a l^{143}$ & Patients with reflux disease $(\mathrm{N}=533)$ & $1.7 \%$ \\
\hline Taiwan & Tseng et al ${ }^{145}$ & Health screening patients who underwent endoscopy ( $N=19$ 812) & $0.061 \%$ \\
\hline
\end{tabular}

factor for BO. Abdominal obesity has been implicated as a risk factor for BO both in the Western world and in Asia. ${ }^{151}{ }^{152} \mathrm{~A}$ recent meta-analysis found that smoking was associated with an increased risk of BO compared with non-GORD controls (OR 1.44; $95 \%$ CI 1.20 to 1.74 ) and population-based controls (OR $1.42 ; 95 \%$ CI 1.15 to 1.76$).{ }^{153}$ This association was also observed by Tseng et al in a Taiwanese study. ${ }^{145}$ Alcohol is not regarded as a risk factor. ${ }^{154} \mathrm{H}$. pylori has been shown to be a negative risk factor in both Asia and the Western world. ${ }^{155}{ }^{156}$ Familial aggregation has been reported in the Western world ${ }^{157-159}$ and may be relevant in Asia. There is possibly a role for genetic predisposition, based on work from genome-wide association studies. ${ }^{160-162}$

CQ24. What is the value of a standard protocol for documenting BO detected at endoscopy?

\section{Statement 24}

A standard protocol for documenting BO using the Prague C \& M criteria at endoscopy will improve the level of diagnostic confidence and aid communication between clinicians.

Agreement: $100 \%$

Quality of evidence: Moderate

Strength of recommendation: Strong

Standardisation of endoscopic documentation of $\mathrm{BO}$ is needed for clinical research and communication between clinicians in order to further research BO, such as its natural course, risk of cancer development and prevention. The Prague C \& M system is used for standardisation. ${ }^{133}$ The Prague C \& M system is widely used by major academic societies such as the American Gastroenterological Association (AGA), ${ }^{123} \mathrm{ACG}^{125}$ and the British Society of Gastroenterology (BSG). ${ }^{5}$

There is a controversy between Japanese and non-Japanese endoscopists regarding the landmark for the gastro-oesophageal junction. The proximal end of the gastric folds is used as the landmark for the gastro-oesophageal junction by the BSG, AGA, $\mathrm{ACG}^{5} 123125$ and other parts of Asia. ${ }^{134} 163$ Japanese endoscopists tend to use the distal end of the palisade vessels to define the gastro-oesophageal junction. Palisade vessels may be anatomically more correct theoretically. ${ }^{164}$ However, the presence of oesophagitis, the degree of air insufflation (minimal for gastric folds and maximal for palisade vessels) as well as respiration and peristalsis can make the correspondence between the two landmarks inconsistent. Thus the consensus group accepted the proximal limits of gastric folds as the definition of the gastrooesophageal junction.

As highlighted earlier, Japanese studies on the epidemiology of $\mathrm{BO}$ have reported high prevalence rates. ${ }^{139}{ }^{140}$ When the entity of USSBO is removed, the prevalence rate of BO in Japan is low, similar to other Asian countries. This highlights the fact that standardisation of definition/documentation is critical for documenting $\mathrm{BO}$ and meaningful interpretation of published data. A minimum endoscopic dataset is shown in table 3. This was adapted from the BSG guidelines. ${ }^{5}$

\section{CQ25. What are the risks of progression to OAC in patients} with $\mathrm{BO}$ ?

Statement 25

The risks of progression to $\mathrm{OAC}$ in patients with $\mathrm{BO}$ increases with male gender, current tobacco smoking, visceral obesity, Caucasian origin, genetic factors, a longer segment, presence of IM and presence of dysplasia.

Agreement: 100\%

Quality of evidence: Moderate

Strength of recommendation: NA

Accumulating evidence supports central or visceral obesity as a predisposing factor for $\mathrm{BO}$ and/or OAC. ${ }^{165}$ Several studies have unequivocally demonstrated that Caucasians have a higher prevalence of BO and OAC. ${ }^{146} 147166$ Recent genome-wide association studies showed that there are susceptibility loci for OAC and BO. ${ }^{162}$ A longer length of $\mathrm{BO}$ has been associated with a higher cancer risk. In a recent meta-analysis it was reported that there was a lower risk of developing OAC in patients with SSBO (1.9/1000 patient years) compared with LSBO (3.3/1000 patient years). However, the confidence limits overlapped, indicating that the evidence was weak. ${ }^{167}$ In a recent prospective cohort study it was also shown that the risk of OAC increased with the length of BO. In this report, subjects with SSBO were shown to have a significantly smaller risk of developing cancer than those with LSBO. Among the subjects 
Table 3 Minimum endoscopic data set for documentation of Barrett's oesophagus (BO)

\begin{tabular}{|c|c|c|}
\hline Finding & Reporting system & Description \\
\hline Length of BO & Prague classification & $\mathrm{CxMx}(\mathrm{x}$ in $\mathrm{cm})$ \\
\hline Barrett's islands & & Describe length and distance from incisors (in $\mathrm{cm}$ ) \\
\hline Hiatus hernia & Distance between diaphragmatic pinch and gastro-oesophageal junction & Yes/no; length in $\mathrm{cm}$ \\
\hline Visible lesions & $\begin{array}{l}\text { Number/distance from incisors }(\mathrm{cm}) \\
\text { Paris classification to describe morphology }\end{array}$ & $\begin{array}{l}\text { Yes/no; distance in } \mathrm{cm} \text {. } \\
0-\mathrm{Ip} \text {, protruded pedunculated } \\
0-\mathrm{Is} \text {, protruded sessile } \\
0-\mathrm{Ila} \text {, superficial elevated } \\
0 \text {-IIb, flat } \\
0-\mathrm{Ilc} \text {, superficial depressed } \\
0-\mathrm{III} \text {, excavated }\end{array}$ \\
\hline Biopsies & Location and number of samples taken & $X$ number ( $X \mathrm{~cm}$ from incisors) \\
\hline
\end{tabular}

with LSBO, the risk ratio appeared to increase linearly with the length of $\mathrm{BO}$, but this was not statistically significant. The other factor to be considered in this study was that the number of biopsies may not have been optimum for LSBO, resulting in inadequate exclusion of dysplasia. ${ }^{168}$

\section{CQ26. What is the value of screening for BO in Asia? Statement 26}

There is no value for screening for BO in the Asia-Pacific region due to the low prevalence rates and lack of benefit.

Agreement: 94.7\%

Quality of evidence: Moderate

Strength of recommendation: Strong

The aim of screening is to detect BO and then enrol these patients in a surveillance programme. This decision has to take into account disease prevalence, potential benefit, potential harm and cost. There are no Asian data available, so this must be extrapolated from Western data. In terms of potential benefit, retrospective case series suggest that OAC may be detected at an earlier stage with a better chance for curative treatment when there is a strategy for screening and subsequent surveillance. ${ }^{169-175}$ A population-based study from the USA did not show any survival benefit from surveillance, ${ }^{176}$ but a recent Dutch population study suggested that proper surveillance will result in lower mortality from OAC. ${ }^{177}$ However, in that study only $8 \%$ of cancers were diagnosed in patients with a prior diagnosis of $\mathrm{BO}$. The potential impact depends on disease prevalence and cancer risk. BO is not common in Asia. Furthermore, the risk of cancer is not high. It must be recognised, however, that $\mathrm{BO}$ is the risk factor for OAC and the only way to detect high-grade dysplasia (HGD) and early cancer is by screening and surveillance. It is recognised that surveillance will not be cost-effective for the majority of patients. ${ }^{178}$ Thus, there is a need to select patients at a higher risk. The BSG and American Society of Gastrointestinal Endoscopy (ASGE) guidelines recommended selecting only patients with a higher risk for screening and subsequent surveillance. ${ }^{5} 179$ Predictive models for BO based on clinical risk factors have been developed based on retrospective data with either prospective or external validation. ${ }^{180-182}$ Since the diagnosis of BO requires histology, endoscopy would be required for screening. For endoscopy, both standard endoscopy and ultrathin transnasal endoscopy without sedation can be utilised. ${ }^{183-186}$ Capsule endoscopy is not recommended as the results are inferior and histology cannot be obtained. ${ }^{186} 187$ Although objective data demonstrating the benefit of screening are limited, there appeared to be patient acceptance for screening. A recent survey suggested that the majority of patients were keen on screening for $\mathrm{BO}$ and most preferred unsedated techniques. ${ }^{188}$ In the last Asia-Pacific GORD consensus, the statement on screening for $\mathrm{BO}$ based on prolonged GORD symptoms was rejected. The rationale was low disease burden and it was recognised that, in Asia, patients with upper GI symptoms would usually undergo diagnostic endoscopic evaluation anyway to exclude peptic ulcer or gastric cancer. ${ }^{4}$

\section{CQ27. Is there evidence for chemoprevention in BO?}

\section{Statement 27}

Limited data suggest that PPI may reduce the risk of progression to dysplasia. The main role for PPI therapy is symptom control and mucosal healing, and not chemoprevention.

Agreement: $89.5 \%$

Quality of evidence: Moderate

Strength of recommendation: Strong

Chemoprevention is the use of pharmacological agents to prevent the development of cancer. Most published data evaluated the use of PPI and non-steroidal anti-inflammatory drugs (NSAIDs). The data supporting the protective effects of PPI in OAC prevention come from several retrospective and prospective observational studies and meta-analyses. ${ }^{5}$ In a recent meta-analysis published in 2014 , Singh et al ${ }^{189}$ showed that PPI use was associated with a $71 \%$ reduction risk of OAC or HGD (OR 0.29; 95\% CI 0.12 to 0.79). Conversely, Hvid-Jensen et $a l^{190}$ performed a nationwide case-control study in Denmark among 9883 patients with newly diagnosed BO, where 140 cases of incident OAC or HGD were identified over a period of 10 years. It was shown that the use of PPI was associated with an increased risk of OAC/HGD. Finally, in another retrospective study investigating differences in exposures in patients with $\mathrm{BO}$ regression, no difference was seen with respect to the use of PPI in patients with regression of BO. ${ }^{191}$

Individual studies have reported inconsistent findings on the association between the use of cyclo-oxygenase (COX) inhibitors such as aspirin and NSAIDs and the risk of neoplastic progression in patients with BO. A recently published meta-analysis showed that, overall, COX inhibitor use was associated with a reduced risk of OAC/HGD among patients with BO (RR 0.64, 95\% CI 0.53 to 0.77$)$. Both aspirin and non-aspirin COX inhibitors reduced the risk of OAC/HGD (RR $0.63,95 \%$ CI 0.43 to 0.94 and RR $0.50,95 \%$ CI 0.32 to 0.78 , respectively). ${ }^{192}$ However, the risk/benefit ratio of aspirin and NSAIDs is unclear, given the risk of GI bleeding and haemorrhagic stroke. The AspECT trial is the biggest multicentre RCT looking at the long-term chemoprevention effect of esomeprazole with or without aspirin. Recruitment has ended and results are awaited. ${ }^{193}$ 
CQ28. What are the benefits of endoscopic surveillance of BO? Statement 28

There is at present no proven benefit in endoscopic surveillance of $\mathrm{BO}$ in the absence of dysplasia.

Agreement: 84.2\%

Quality of evidence: Moderate

Strength of recommendation: Strong

So far no clear benefit has been proven for endoscopic surveillance of $\mathrm{BO}$ in the absence of dysplasia. The data on the risk of progression of non-dysplastic BO are reviewed in Statement 30. When there is associated low-grade dysplasia (LGD), surveillance will be more relevant because disease progression may occur at a faster rate and thus surveillance may have a higher yield of detecting neoplastic progression. It would be difficult to recommend endoscopic surveillance of $\mathrm{BO}$, considering the low risk of malignant progression particularly in Asians, if it is not associated with dysplasia given the high costs. Studies have shown that the prediction of progression of oesophageal dysplasia is improved if at least two expert pathologists agree on the diagnosis and increases further when a greater number of pathologists concur with the diagnosis. Thus, dysplasia should be confirmed by a second pathologist. ${ }^{124} 194195$ According to the AGA and BSG guidelines, surveillance of non-dysplastic BO is recommended at 3-5-year intervals. ${ }^{5}{ }^{124}$ However, a recent report argues that this strategy may not be cost-effective in the majority of patients with BO. ${ }^{178}$ The decision for surveillance of $\mathrm{BO}$ without dysplasia in Asia has to be individualised, given the lack of robust data. Even if the Western strategy of 3-5-yearly surveillance is adopted, the issue of when to stop if no dysplasia is repeatedly detected is also unclear. Should one stop after three surveillance procedures if no dysplasia is detected? Should one stop after age 85 years? It is only when LGD is unequivocally demonstrated that surveillance should be done according to the BSG/AGA guidelines, given the risk of progression. When HGD is detected, intervention such as endoscopic resection rather than continued surveillance for progression to OAC would be recommended. This is because it has been shown that synchronous cancer can occur with HGD. ${ }^{196}$

CQ29. What is the advantage of advanced imaging endoscopic techniques over WLE in detecting dysplasia/cancer in BO? Statement 29

Advanced endoscopic imaging techniques facilitate targeted biopsies and increase the detection rate of dysplasia. As a minimum, high resolution/definition WLE should be used for endoscopic imaging.

Agreement: 94.7\%

Quality of evidence: Moderate

Strength of recommendation: Strong

As a minimum, diagnostic evaluation should be performed using high resolution or definition WLE (HD-WLE). In addition, advanced imaging techniques may increase the detection rate of dysplasia. Advanced imaging techniques either enhance mucosal surface contrast or provide magnification of mucosal surface details, with or without concomitant mucosal surface contrast. Chromoendoscopy enhances mucosal surface contrast by dye spray, such as the use of indigo carmine. Virtual chromoendoscopy provides mucosal surface contrast electronically without the use of dye spray. It may be achieved with the use of an optical filter (NBI), blue laser imaging (BLI) or with electronic processing (i-scan, flexible intelligent color enhancement (FICE)). Magnifying endoscopy combined with chromoendoscopy or virtual chromoendoscopy is able to visualise the mucosal microsurface and microvessel patterns and differentiate
Table 4 Overview of imaging modalities

\begin{tabular}{|c|c|}
\hline Imaging technique & Comment \\
\hline HD-WLE & Becoming the default standard \\
\hline Magnification endoscopy & $\begin{array}{l}\text { Evaluated in case series; not directly } \\
\text { compared with standard endoscopy } \\
\text { Only allows visualisation of very focal areas }\end{array}$ \\
\hline Chromoendoscopy & $\begin{array}{l}\text { Relatively inexpensive to use } \\
\text { Variability in use of stains and spray catheter } \\
\text { Lack of standardisation of technique }\end{array}$ \\
\hline $\begin{array}{l}\text { Virtual chromoendoscopy (eg, } \\
\text { NBI, BLI, FICE, i-scan) }\end{array}$ & $\begin{array}{l}\text { Relatively easy to use, showing yield that is } \\
\text { similar to that of routine biopsies } \\
\text { Can be combined with magnification } \\
\text { endoscopy to enhance imaging of mucosa } \\
\text { surface }\end{array}$ \\
\hline Autofluorescence imaging & $\begin{array}{l}\text { Allows broad-based imaging } \\
\text { High false positive rates with subjective } \\
\text { colour interpretation }\end{array}$ \\
\hline Confocal microscopy & $\begin{array}{l}\text { High quality and detailed imaging } \\
\text { Challenges include imaging of very focal } \\
\text { areas, intravenous fluorescence agent and } \\
\text { image interpretation }\end{array}$ \\
\hline
\end{tabular}

areas of HGD/OAC from non-dysplastic areas. Other advanced techniques include autofluorescence imaging and ultrahigh magnification with the use of confocal laser microendoscopy, but these are of limited clinical utility. The characteristics of such techniques are summarised in table 4.

Advanced endoscopic imaging has been investigated to determine whether it can increase the detection of both IM and dysplasia in BO. Most of the studies used NBI. ${ }^{129}$ 197-199 In an international multicentre randomised trial, Sharma et al compared HD-WLE and NBI for detection of IM and neoplasia in BO. During HD-WLE, four quadrant biopsies every $2 \mathrm{~cm}$, together with targeted biopsies of visible lesions (Seattle protocol), were obtained. During NBI examination, mucosal and vascular patterns were noted and targeted biopsies were obtained. Both HD-WLE and NBI detected 104/113 (92\%) patients with IM, but NBI required fewer biopsies per patient (3.6 vs 7.6, $\mathrm{p}<0.0001)$. NBI detected a higher proportion of areas with dysplasia (30\% vs $21 \%, \mathrm{p}=0.01)$. During examination with NBI, all areas of HGD and cancer had an irregular mucosal or vascular pattern. It was concluded that NBI-targeted biopsies can have the same IM detection rate as an HD-WLE examination with the Seattle protocol while requiring fewer biopsies. In addition, NBI-targeted biopsies can detect more areas with dysplasia. Regular appearing NBI surface patterns did not harbour HGD/ cancer, suggesting that biopsies could be avoided in these areas. ${ }^{199}$ In a recent meta-analysis, Song et al reported that NBI had a sensitivity and specificity of 0.91 (95\% CI 0.86 to 0.94 ) and 0.85 (95\% CI 0.76 to 0.92 ) on a per-patient element, and 0.97 (95\% CI 0.95 to 0.98$)$ and 0.64 (95\% CI 0.59 to 0.68$)$ on a per-lesion element for IM diagnosis, respectively. The per-patient sensitivity and specificity for identifying HGD were 0.91 (95\% CI 0.75 to 0.98 ) and 0.95 (95\% CI 0.91 to 0.97$).{ }^{200}$ FICE has also been reported to have a good diagnostic value. ${ }^{201} 202$

\section{CQ30. How frequently should a patient with BO without LGD} undergo endoscopy in a surveillance programme?

Statement 30

If it is decided to perform surveillance in the absence of dysplasia, oesophagogastroduodenoscopy should be performed every 3-5 years with targeted biopsies using a standardised protocol. 
Agreement: $94.7 \%$

Quality of evidence: Moderate

Strength of recommendation: Strong

The above statement is based on expert opinion and evidence from observational studies evaluating the progression of non-dysplastic BO to OAC. The progression of non-dysplastic $\mathrm{BO}$ to $\mathrm{OAC}$ is estimated to range from $0.27 \%$ to $0.59 \%$ / year. ${ }^{203-206}$ In a nationwide population-based cohort study in Denmark between 1992 and 2009, the absolute annual risk of OAC was calculated at $0.12 \%$ among 11028 patients with BO. ${ }^{203}$ A multicentre study of a large cohort of patients with BO evaluated the risk of progression in patients with nondysplastic BO $(n=1204) .{ }^{205}$ The mean time to progression to OAC was calculated at 5.29 years (range 1.05-15.3). The incidence of HGD and OAC was $0.63 \%$ year $(95 \%$ CI $0.47 \%$ to $0.86 \%$ ) while the incidence of LGD was $3.6 \% /$ year $(95 \%$ CI $3.2 \%$ to $4.1 \%$ ). Five and 10 years after diagnosis, $98.6 \%$ and $97.1 \%$ of patients with non-dysplastic BO were cancer-free, respectively. Another study examined whether persistence of non-dysplastic BO independently protected against development of cancer $(n=1401) .{ }^{206}$ In the study, five groups of patients were identified. Patients in group 1 were found to have nondysplastic BO at their first endoscopy. Patients in group 2 were found to have non-dysplastic BO on their first two consecutive endoscopies. Similarly, patients in groups 3, 4 and 5 were found to have non-dysplastic $\mathrm{BO}$ on three, four and five consecutive surveillance endoscopies. The median follow-up period was 5 \pm 3.9 years (7846 patient-years). The annual risk of OAC in groups $1-5$ was $0.32 \%, 0.27 \%, 0.16 \%, 0.2 \%$ and $0.11 \%$, respectively ( $\mathrm{p}$ for trend $=0.03$ ). It was concluded that persistence of non-dysplastic BO, based on multiple surveillance endoscopies, was associated with a gradually lower likelihood of progression to OAC. Cost-effectiveness analyses have shown that surveillance every 5 years is the only effective strategy for non-dysplastic BO surveillance. ${ }^{205} 207$ On the other hand, it is not clear if surveillance improves mortality from OAC.

CQ31. How should a patient with BO with LGD be treated? Statement 31

For BO with confirmed LGD, consider treatment or surveillance. If treatment is chosen, resect the lesion if it is endoscopically identifiable as a focal lesion. In the absence of focal lesions, consider radiofrequency ablation (RFA). If surveillance is chosen, repeat endoscopy in 6 months to confirm LGD.

Agreement: 94.7\%

Quality of evidence: Moderate

Strength of recommendation: Strong

The diagnosis of LGD is challenging even to expert GI pathologists. In a study by Vennalaganti, despite refining the histopathology criteria to diagnose LGD, inter-observer agreement among expert pathologists continued to remain low $(0.07-0.33) .{ }^{208}$ Due to the lack of a reliable histopathological diagnosis, the estimated rates of progression of LGD to OAC are highly variable $(0.5 \%-13.6 \%$ year $)$. In a meta-analysis published in 2014, the annual incidence rate of OAC in patients with LGD was $0.54 \%(95 \%$ CI $0.09 \%$ to $0.15 \%) .{ }^{209}$ In another recently conducted European multicentre RCT in patients with LGD, 68 were randomised to RFA and 68 to endoscopic surveillance. $^{210}$ RFA reduced the risk of progression to OAC by $7.4 \%(1.5 \%$ for ablation vs $8.8 \%$ for control; $95 \%$ CI $0 \%$ to $14.7 \% ; \mathrm{p}=0.03)$. Due to the lack of reliable diagnosis and progression rates for LGD, the recommendations for treatment should be individualised.
CQ32. What are the treatment options for BO with HGD?

Statement 32

Endoscopic resection is the treatment of choice for $\mathrm{BO}$ with HGD and carcinoma in situ when the lesion can be localised endoscopically. RFA is recommended to ablate all BO to treat undetected synchronous lesions and to prevent development of metachronous lesions. Surgery can be an alternative to endoscopic resection (with or without RFA).

Agreement: 100\%

Quality of evidence: Moderate

Strength of recommendation: Strong

Currently, endoscopic resection is the preferred treatment modality for BO with HGD, intramucosal cancer (T1aEP (lesion extension limited in the epithelium, which is equivalent to Tis) and T1aLP (lesion extension remained in the lamina propria)). ${ }^{211}$ It is not the absolute indication for the T1aMM lesion (extending to the muscularis mucosa) as there is a chance of lymph node metastasis in about $50 \%$ of cases. Compared with surgery, responses to endoscopic resection and ablative therapies were much better. ${ }^{212}$ In a study by Pech et al, ${ }^{213}$ complete response was reported in $97 \%$ of patients undergoing endoscopic resection and other ablative procedures for BO-related neoplasia, with a 5 -year survival rate of $84 \%$. Surveillance biopsies in patients showed normal squamous epithelium in $97 \%$ of patients with a mean remission time of 23 months. In contrast, a systematic review of 23 studies involving 441 cases showed that, on average, $40 \%$ of patients who had undergone oesophagectomy for HGD developed cancer on follow-up. ${ }^{214}$ Thus, oesophagectomy should be reserved for cases with submucosal invasion, lymph node metastasis or when endoscopic therapy fails. ${ }^{215}$

RFA should be employed after endoscopic resection to ablate all BO epithelium because of the risk of undetected synchronous lesions and to prevent the development of metachronous lesions. $^{216}$ By itself, RFA is considered to be an inadequate method for the cure of BO-associated neoplasia, as cases of relapse from buried cancer foci are increasingly documented. In a large multicentre study by Gupta et al, ${ }^{217}$ although $56 \%$ of patients treated with RFA were in complete remission after 24 months, $33 \%$ of these patients had disease recurrence within the next 2 years.

\section{DISCUSSION}

The third consensus on GORD in the Asia-Pacific region continues to clarify the investigation and treatment of GORD which has been rising in incidence throughout the region. The report shows that there are similarities and differences between the region and the Western world in the management of GORD. The role of the declining prevalence of $H$. pylori infection was controversial. Epidemiological data showed an inverse association between $H$. pylori infection and GORD, but causality has not been proven. The decline in H. pylori prevalence is related to improved living conditions, less overcrowding and improved sanitation. Eradication of $H$. pylori for treatment of $H$. pylori-related diseases has led to a decline of $H$. pylori infection in the region. Four recent meta-analyses have been performed on the development of GORD after $H$. pylori eradication. $^{218-221}$ Three studies reported no association between $H$. pylori eradication and the development of GORD or GORD symptoms. ${ }^{218-220}$ A fourth study, however, concluded that eradication of $H$. pylori infection may be a risk factor for de novo endoscopic GORD, especially in the Asian population. $^{221}$ In a community-based study of gastric cancer 
prevention in Matsu Island, Taiwan, through mass eradication of $H$. pylori infection the annual incidence of oesophagitis was $6 \%$ (95\% CI $5.1 \%$ to 6.9\%). Male gender and large waist circumference were associated with the development of oesophagitis after $H$. pylori treatment. ${ }^{222}$ The biological mechanism for the development of GORD following $H$. pylori eradication depends on the distribution of gastritis (hyper- or hypo-acidity) and predisposition to GORD (hiatus hernia, gastro-oesophageal junction competence, oesophageal acid clearance). In 2000, Hamada et al documented that Japanese patients who developed reflux oesophagitis after $H$. pylori eradication had a greater prevalence of hiatus hernia and more severe corpus gastritis. A longitudinal study of patients over 10 years following eradication therapy demonstrated that oesophagitis was mild and transient in $40 \%$ of patients and established oesophagitis was present in only $4.4 \%$ of patients. ${ }^{223}$ The incidence of OAC has been increasing whereas that of gastric cancer is decreasing. Derakhshan et al investigated whether the incidences of these two cancers and their time trends might be inversely related, pointing to a common environmental factor exerting opposite effects on these cancers. Data were abstracted from 'Cancer Incidence in Five Continents' (CI5) Volume X, GLOBOCAN 2012 and CI5C-Plus. Superimposition of longitudinal and crosssectional data indicated that populations with a current high incidence of OAC and a low incidence of gastric cancer had previously resembled countries with a high incidence of gastric cancer and a low incidence of OAC. This negative association between gastric cancer and OAC in both current incidences and time trends was consistent with a common environmental factor predisposing to one and protecting from the other. $\mathrm{H}$. pylori atrophic gastritis was postulated as a possible factor. ${ }^{224}$

Patients with symptoms that are partially or completely nonresponsive to PPI are regarded as having PPI-refractory GORD. In this consensus meeting we made a distinction between the disease GORD and the symptoms which are refractory to PPI. The diagnostic approach for this group of patients is summarised in two algorithms. One algorithm is targeted at areas with access to endoscopy and functional testing and when the patient is agreeable (figure 1). In areas where functional testing is unavailable or where the patient does not wish to undergo the tests, a series of therapeutic trials can be given (figure 2). Before patients are subjected to surgical treatment, however, functional testing is mandatory as antireflux surgery in patients with achalasia, for example, would aggravate the condition further.

Vonoprazan, a potassium-competitive acid blocker, has been developed for the treatment of acid-related diseases. However, it was not formally discussed or voted upon during the consensus meeting due to lack of data at that time. Since then, a multicentre randomised comparison with lansoprazole has been reported and the results showed non-inferiority with lansoprazole and it was also effective in CYP2C19 extensive metabolisers. ${ }^{225}$

In this consensus, the diagnosis of $\mathrm{BO}$ has been further refined and standardised. There is no longer a requirement for the presence of intestinal metaplasia, although the higher risk of progression in the presence of IM is acknowledged. This is consistent with the BSG guidelines ${ }^{5}$ and the recently published report by the international Benign Barrett's and Cancer Taskforce (BOB CAT) consensus group. ${ }^{226}$ It must be acknowledged that this does differ from the American and Australian guidelines with respect to the requirement of the presence of IM. ${ }^{123} 227$ The entity of USSBO has been removed and the minimum length of columnar lined oesophagus required is $1 \mathrm{~cm}$. Once BO is detected, the decision concerning surveillance needs to be individualised because there is at present no proven benefit in endoscopic surveillance of BO in the absence of dysplasia. If surveillance is undertaken, HD-WLE as well as advanced endoscopic imaging techniques such as NBI with magnification should be used to facilitate targeted biopsies and increase the detection rate of dysplasia. In the presence of HGD and intramucosal cancer, the group recommends endoscopic intervention when feasible, given the risk for progression to $\mathrm{OAC}$ and the data supporting efficacy and safety of minimally invasive options such as endoscopic resection and RFA.

\section{Author affiliations}

'Department of Gastroenterology and Hepatology, Changi General Hospital, Singapore, Singapore

${ }^{2}$ Faculty of Health and Medicine, University of Newcastle, Callaghan, New South Wales, Australia

${ }^{3}$ Division of Gastroenterology and Hepatology, Department of Medicine, University of Malaya, Kuala Lumpur, Malaysia

${ }^{4}$ Department of Medicine, Jichi Medical University, Tochigi, Japan

${ }^{5}$ Gastroenterology Department, Concord Hospital, University of Sydney, Sydney, New

South Wales, Australia

${ }^{6}$ Faculty of Medicine and Biomedical Sciences, The University of Queensland, Brisbane, Queensland, Australia

${ }^{7}$ Northwestern University Feinberg School of Medicine, Chicago, Illinois, USA

${ }^{8}$ University of Kansas and VA Medical Center, Kansas City, Kansas, USA

${ }^{9}$ Department of Comprehensive Medicine, Tohoku University, Sendai, Japan

${ }^{10}$ Department of Medicine and Therapeutics, The Chinese University of Hong Kong,

Shatin, China

${ }^{11}$ Division of Gastroenterology, The First Affiliated Hospital, Sun Yat-sen University,

Guangzhou, China

${ }^{12}$ Department of Internal Medicine, College of Medicine, The Catholic University of

Korea, Seoul, Korea

${ }^{13}$ Department of Internal Medicine, National Cheng Kung University Hospital,

Medical College, National Cheng Kung University, Tainan, Taiwan

${ }^{14}$ The Second Affiliated Hospital, Xian Jiaotong University, Xian, China

${ }^{15}$ Division of Gastroenterology and Hepatology, National University Hospital,

Singapore, Singapore

${ }^{16}$ Department of Medicine, University of Sano Tomas, Manila, Philippines

${ }^{17}$ Faculty of Medicine, University of Indonesia, Jakarta, Indonesia

${ }^{18}$ Faculty of Medicine, Ramathibodi Hospital, Mahidol University, Bangkok, Thailand

${ }^{19}$ Department of Gastroenterology, Seth GS Medical College and King Edward

Memorial Hospital, Mumbai, India

Acknowledgements The consensus meeting was supported by the Asian Pacific Association of Gastroenterology.

Contributors KMF, KLG and KS planned the meeting and prepared the clinical questions. All faculty members were involved in developing the statements with supporting evidence and drafted the text of discussion relevant to their statements. KMF, KS, NT, PK and TLA wrote the initial draft of the manuscript. All faculty members read, helped to refine and approved the final manuscript.

Funding Educational grant from the Asian Pacific Association of Gastroenterology.

Competing interests KMF has received lecture fees from Astra Zeneca and Reckitt Benckiser. NT has received lecture and/or consulting fees from Rome Foundation, GI Therapies, Yuhan, Adelphi Values, Prometheus, Janssen, Abbott Pharmaceuticals, Pfizer and Salix. KLG has received lecture and/or advisory board fees from Astra Zeneca, Eisai and Takeda. KS has received lecture fees from Takeda. GH has shares in Bayer. JP has received lecture and/or consulting fees from Astra Zeneca, Takeda, Medtronic, Sandhill and Ironwood. TLA has received lecture fees from Eisai and Takeda. MH has received lecture and/or consulting fees from Astra Zeneca, Daiichi-Sankyo, Takeda, Astellas, Zeria Pharmaceutical, Mylan EPD GK and Tsumura.

JW has received lecture and advisory board fees from Astra Zeneca, Reckitt Benckiser and Takeda. MC has received lecture fees from Astra Zeneca, Eisai, Takeda and Abbott. JS has received lecture fees from Astra Zeneca, Eisai and Takeda.

Provenance and peer review Not commissioned; externally peer reviewed.

\section{REFERENCES}

1 Katz PO, Gerson LB, Vela MF. Guidelines for the diagnosis and management of gastroesophageal reflux disease. Am J Gastroenterol 2013;108:308-28.

2 Kahrilas PJ, Shaheen NJ, Vaezi MF. American Gastroenterological Association Medical Position Statement on the management of gastroesophageal reflux disease. Gastroenterology 2008;135:1383-91, 1391.e1-5. 
3 Fock KM, Talley N, Hunt R, et al. Report of the Asia-Pacific consensus on the management of gastroesophageal reflux disease. J Gastroenterol Hepatol 2004; 19:357-67.

4 Fock KM, Talley NJ, Fass R, et al. Asia-Pacific consensus on the management of gastroesophageal reflux disease: update. J Gastroenterol Hepatol 2008;23:8-22.

5 Fitzgerald RC, di Pietro M, Ragunath K, et al. British Society of Gastroenterology guidelines on the diagnosis and management of Barrett's oesophagus. Gut 2014;63:7-42.

6 Guyatt GH, Oxman AD, Vist GE, et al. GRADE: an emerging consensus on rating quality of evidence and strength of recommendations. BMJ 2008;336:924-6.

7 Hung LJ, Hsu PI, Yang CY, et al. Prevalence of gastroesophageal reflux disease in a general population in Taiwan. J Gastroenterol Hepatol 2011;26:1164-8.

8 Kumar S, Sharma S, Norboo T, et al. Population based study to assess prevalence and risk factors of gastroesophageal reflux disease in a high altitude area. Indian J Gastroenterol 2011;30:135-43.

9 Chang FY. Variations in the reported prevalence of gastroesophageal reflux disease in Taiwan. J Clin Med Assoc 2012;75:91-2.

10 Wang FW, Tu MS, Chuang HY, et al. Erosive esophagitis in asymptomatic subjects: risk factors. Dig Dis Sci 2010;55:1320-4.

11 Chen MJ, Lee YC, Chiu HM, et al. Time trends of endoscopic and pathological diagnoses related to gastroesophageal reflux disease in a Chinese population: eight years single institution experience. Dis Esophagus $2010 ; 23: 201-7$.

12 Bhatia SJ, Reddy DN, Ghoshal UC, et al. Epidemiology and symptom profile of gastroesophageal reflux in the Indian population: report of the Indian Society of Gastroenterology Task Force. Indian J Gastroenterol 2011;30:118-27.

13 Sharma PK, Ahuja V, Madan K, et al. Prevalence, severity, and risk factors of symptomatic gastroesophageal reflux disease among employees of a large hospital in northern India. Indian J Gastroenterol 2011;30:128-34.

14 He J, Ma X, Zhao Y, et al. A population-based survey of the epidemiology of symptom-defined gastroesophageal reflux disease: the Systematic Investigation of Gastrointestinal Diseases in China. BMC Gastroenterol 2010;10:94.

15 Zou D, He J, Ma X, et al. Epidemiology of symptom-defined gastroesophageal reflux disease and reflux esophagitis: the Systematic Investigation of Gastrointestinal Diseases in China (SILC). Scand J Gastroenterol 2011;46:133-41.

16 Bai Y, Du Y, Zou D, et al. Gastroesophageal Reflux Disease Questionnaire (GORDQ) in real-world practice: a national multicenter survey on 8065 patients. J Gastroenterol Hepatol 2013;28:626-31.

17 Kim KM, Cho YK, Bae SJ, et al. Prevalence of gastroesophageal reflux disease in Korea and associated health-care utilization: a national population-based study. J Gastroenterol Hepatol 2012;27:741-5.

18 Goh KL. Gastroesophageal reflux disease in Asia: a historical perspective and present challenges. J Gastroenterol Hepatol 2011;26(Suppl 1):2-10.

19 Corley DA, Kubo A. Body mass index and gastroesophageal reflux disease: a systematic review and meta-analysis. Am J Gastroenterol 2006;101:2619-28.

20 Asia Pacific Cohort Studies Collaboration. The burden of overweight and obesity in the Asia-Pacific region. Obes Rev 2007;8:191-6.

21 Gunji T, Sato H, lijima K, et al. Risk factors for erosive esophagitis: a cross-sectional study of a large number of Japanese males. J Gastroenterol 2011;46:448-55.

22 Kim N, Lee SW, Cho SI, et al, H. pylori and GORD Study Group of Korean College of Helicobacter and Upper Gastrointestinal Research. The prevalence of and risk factors for erosive oesophagitis and non-erosive reflux disease: a nationwide multicentre prospective study in Korea. Aliment Pharmacol Ther 2008;27:173-85.

23 Ashktorab H, Entezari O, Nouraie M, et al. Helicobacter pylori protection against reflux esophagitis. Dig Dis Sci 2012;57:2924-8.

24 Sonnenberg A, Lash RH, Genta RM. A national study of Helicobactor pylori infection in gastric biopsy specimens. Gastroenterology 2010;139:1894-1901.e2; quiz e12.

25 Ho KY, Chan YH, Kang JY. Increasing trend of reflux esophagitis and decreasing trend of Helicobacter pylori infection in patients from a multi-ethnic Asian country. Am J Gastroenterol 2005;100:1923-8.

26 Katelaris PH, Ha VM, Robertson G, et al. Marked increase in erosive oesophagitis in Vietnamese migrants to Australia compared with indigenous Vietnamese, despite identical H. pylori prevalence. International Workshop on Gastroduodenal Pathology and Helicobacter pylori. Gut 2002;5(Suppl 2):A69.

27 Chung SJ, Lim SH, Choi J, et al. Helicobacter pylori serology inversely correlated with the risk and severity of reflux esophagitis in Helicobacter pylori endemic area: a matched case-control study of 5,616 health check-up Koreans. J Neurogastroenterol Motil 2011;17:267-73.

28 Jung HK. Epidemiology of gastroesophageal reflux disease in Asia: a systematic review. J Neurogastroenterol Motil 2011;17:14-27.

29 Cho YS, Choi MG, Jeong JJ, et al. Prevalence and clinical spectrum of gastroesophageal reflux: a population-based study in Asan-si, Korea. Am J Gastroenterol 2005;100:747-53.

30 Wang JH, Luo JY, Dong L, et al. Epidemiology of gastroesophageal reflux disease: a general population-based study in Xi'an of Northwest China. World J Gastroenterol 2004;10:1647-51.
31 Lee HS, Jeon SW. Barrett esophagus in Asia: same disease with different pattern. Clin Endosc 2014;47:15-22.

32 Chang CY, Cook MB, Lee YC, et al., Asian Barrett's Consortium. Current status of Barrett's esophagus research in Asia. J Gastroenterol Hepatol 2011;26:240-6.

33 Shim KN, Hong SJ, Sung JK, et al. Clinical spectrum of reflux esophagitis among 25,536 Koreans who underwent a health check-up: a nationwide multicenter prospective, endoscopy-based study. J Clin Gastroenterol 2009;43:632-8.

34 Ho KY, Ng WL, Kang JY, et al. Gastroesophageal reflux disease is a common cause of noncardiac chest pain in a country with a low prevalence of reflux esophagitis. Dig Dis Sci 1998;43:1991-7.

35 Kim BJ, Choi SC, Kim JJ, et al. Pathological bolus exposure plays a significant role in eliciting non-cardiac chest pain. J Gastroenterol Hepatol 2010;25:1855-60.

36 Mohd H, Qua CS, Wong CH, et al. Non-cardiac chest pain: prevalence of reflux disease and response to acid suppression in an Asian population. J Gastroenterol Hepatol 2009;24:288-93.

37 Wong WM, Lai KC, Lau CP, et al. Upper gastrointestinal evaluation of Chinese patients with non-cardiac chest pain. Aliment Pharmacol Ther 2002;16:465-71.

38 Sweis R, Fox M, Anggiansah A, et al. Prolonged, wireless pH-studies have a high diagnostic yield in patients with reflux symptoms and negative $24-h$ catheter-based pH-studies. Neurogastroenterol Motil 2011;23:419-26.

39 Wang WH, Huang JQ, Zheng GF, et al. Is proton pump inhibitor testing an effective approach to diagnose gastroesophageal reflux disease in patients with noncardiac chest pain? A meta-analysis. Arch Intern Med 2005;165:1222-8.

40 Wu JC. Is longer duration of proton pump inhibitor trial better for gastroesophageal reflux disease-related non-cardiac chest pain? J Gastroenterol Hepatol 2009;24:1477-8.

41 Belafsky PC, Postma GN, Koufman JA. The validity and reliability of the reflux finding score (RFS). Laryngoscope 2001;111:1313-17.

42 Chung JH, Tae K, Lee YS, et al. The significance of laryngopharyngeal reflux in benign vocal mucosal lesions. Otolaryngol Head Neck Surg 2009;141:369-73.

43 Poelmans J, Feenstra L, Demedts I, et al. The yield of upper gastrointestinal endoscopy in patients with suspected reflux-related chronic ear, nose, and throat symptoms. Am J Gastroenterol 2004;99:1419-26.

44 Yuksel ES, Slaughter JC, Mukhtar N, et al. An oropharyngeal pH monitoring device to evaluate patients with chronic laryngitis. Neurogastroenterol Motil 2013;25:e315-23.

45 Kavitt RT, Yuksel ES, Slaughter JC, et al. The role of impedance monitoring in patients with extraesophageal symptoms. Laryngoscope 2013;123:2463-8.

46 Lam $\mathrm{P}$, Wei Wl, Hui $\mathrm{Y}$, et al. Prevalence of $\mathrm{pH}$-documented laryngopharyngeal reflux in Chinese patients with clinically suspected reflux laryngitis. Am J Otolaryngol 2006;27:186-9.

47 El-Serag H, Becher A, Jones R. Systematic review: persistent reflux symptoms on proton pump inhibitor therapy in primary care and community studies. Aliment Pharmacol Ther 2010;32:720-37.

48 Niu XP, Yu BP, Wang YD, et al. Risk factors for proton pump inhibitor refractoriness in Chinese patients with non-erosive reflux disease. World $J$ Gastroenterol 2013;19:3124-9.

49 Lee ES, Kim N, Lee SH, et al. Comparison of risk factors and clinical responses to proton pump inhibitors in patients with erosive oesophagitis and non-erosive reflux disease. Aliment Pharmacol Ther 2009;30:154-64.

50 Miwa H, Sasaki M, Furuta T, et al. Efficacy of rabeprazole on heartburn symptom resolution in patients with non-erosive and erosive gastro-oesophageal reflux disease: a multicenter study from Japan. Aliment Pharmacol Ther 2007;26:69-77.

51 Bytzer $\mathrm{P}$, van Zanten SV, Mattsson $\mathrm{H}$, et al. Partial symptom-response to proton pump inhibitors in patients with non-erosive reflux disease or reflux oesophagitis -a post hoc analysis of 5796 patients. Aliment Pharmacol Ther 2012;36:635-43.

52 Becher A, El-Serag H. Systematic review: the association between symptomatic response to proton pump inhibitors and health-related quality of life in patients with gastro-oesophageal reflux disease. Aliment Pharmacol Ther 2011;34:618-27.

53 Tack J, Becher A, Mulligan C, et al. Systematic review: the burden of disruptive gastro-oesophageal reflux disease on health-related quality of life. Aliment Pharmacol Ther 2012;35:1257-66.

54 Hongo M, Miwa H, Kusano M. Symptoms and quality of life in underweight gastroesophageal reflux disease patients and therapeutic responses to proton pump inhibitors. J Gastroenterol Hepatol 2012;27:913-18.

55 Kim JY, Kim N, Seo PJ, et al. Association of sleep dysfunction and emotional status with gastroesophageal reflux disease in Korea. J Neurogastroenterol Motil 2013;19:344-54.

56 Yang $\mathrm{XL}$, Liu XH, Ke MY, et al. Long-term impact on quality of life in patients with gastroesophageal reflux disease after 52-week rabeprazole treatment. Zhonghua Yi Xue Za Zhi 2009;89:2404-7.

57 Ahlawat SK, Mohi-Ud-Din R, Williams DC, et al. A prospective study of gastric acid analysis and esophageal acid exposure in patients with gastroesophageal reflux refractory to medical therapy. Dig Dis Sci 2005;50:2019-24.

58 Clayton SB, Rife CC, Singh ER, et al. Twice-daily proton pump inhibitor therapy does not decrease the frequency of reflux episodes during nocturnal recumbency in 
patients with refractory GORD: analysis of 200 patients using multichannel intraluminal impedance-pH testing. Dis Esophagus 2012;25:682-6.

59 Yamashita H, Ashida K, Fukuchi T, et al. Combined pH-impedance monitoring and high-resolution manometry of Japanese patients treated with proton-pump inhibitors for persistent symptoms of non-erosive reflux disease. J Smooth Muscle Res 2012;48:125-35.

60 Kohata Y, Fujiwara Y, Machida H, et al. Pathogenesis of proton-pump inhibitor-refractory non-erosive reflux disease according to multichannel intraluminal impedance-pH monitoring. J Gastroenterol Hepatol 2012;27(Suppl 3):58-62.

61 Zschau NB, Andrews JM, Holloway RH, et al. Gastroesophageal reflux disease after diagnostic endoscopy in the clinical setting. World I Gastroenterol 2013;19:2514-20.

62 Lee YC, Lin JT, Wang HP, et al. Influence of cytochrome P450 2C19 genetic polymorphism and dosage of rabeprazole on accuracy of proton-pump inhibitor testing in Chinese patients with gastroesophageal reflux disease. J Gastroenterol Hepatol 2007;22:1286-92.

63 Furuta T, Sugimoto M, Kodaira C, et al. CYP2C19 genotype is associated with symptomatic recurrence of GORD during maintenance therapy with low-dose lansoprazole. Eur J Clin Pharmacol 2009;65:693-8.

64 Thompson SK, Cai W, Jamieson GG, et al. Recurrent symptoms after fundoplication with a negative $\mathrm{pH}$ study —recurrent reflux or functional heartburn? J Gastrointest Surg 2009;13:54-60.

65 Miwa H, Minoo T, Hojo M, et al. Oesophageal hypersensitivity in Japanese patients with non-erosive gastro-oesophageal reflux diseases. Aliment Pharmacol Ther 2004;20(Suppl 1):112-17.

66 Nagahara A, Miwa H, Minoo T, et al. Increased esophageal sensitivity to acid and saline in patients with nonerosive gastro-esophageal reflux disease. J Clin Gastroenterol 2006;40:891-5.

67 Sá CC, Kishi HS, Silva-Werneck AL, et al. Eosinophilic esophagitis in patients with typical gastroesophageal reflux disease symptoms refractory to proton pump inhibitor. Clinics (Sao Paulo) 2011;66:557-61.

68 Foroutan M, Norouzi A, Molaei M, et al. Eosinophilic esophagitis in patients with refractory gastroesophageal reflux disease. Dig Dis Sci 2010;55:28-31.

69 Fujishiro H, Amano Y, Kushiyama Y, et al. Eosinophilic esophagitis investigated by upper gastrointestinal endoscopy in Japanese patients. I Gastroenterol 2011;46:1142-4.

70 Dellon ES, Jensen ET, Martin CF, et al. Prevalence of eosinophilic esophagitis in the United States. Clin Gastroenterol Hepatol 2014;12:589-96.

71 Fujiwara Y, Sugawa T, Tanaka F, et al. A multicenter study on the prevalence of eosinophilic esophagitis and PPI-responsive esophageal eosinophilic infiltration. Intern Med 2012;51:3235-9.

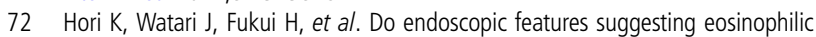
esophagitis represent histological eosinophilia? Dig Endosc 2014;26:156-63.

73 Shimura S, Ishimura N, Tanimura T, et al. Reliability of symptoms and endoscopic findings for diagnosis of esophageal eosinophilia in a Japanese population. Digestion 2014;90:49-57.

74 Shi YN, Sun SJ, Xiong LS, et al. Prevalence, clinical manifestations and endoscopic features of eosinophilic esophagitis: a pathological review in China. J Dig Dis 2012:13:304-9.

75 Joo MK, Park JJ, Kim SH, et al. Prevalence and endoscopic features of eosinophilic esophagitis in patients with esophageal or upper gastrointestinal symptoms. J Dig Dis 2012;13:296-303.

76 Poh CH, Gasiorowska A, Navarro-Rodriguez T, et al. Upper GI tract findings in patients with heartburn in whom proton pump inhibitor treatment failed versus those not receiving anti-reflux treatment. Gastrointest Endosc 2010;71:28-34.

77 Fock KM, Teo EK, Ang TL, et al. The utility of narrow band imaging in improving the endoscopic diagnosis of gastroesophageal reflux disease. Clin Gastroenterol Hepatol 2009:7:54-9.

78 Sharma P, Wani S, Bansal A, et al. A feasibility trial of narrow band imaging endoscopy in patients with gastroesophageal reflux disease. Gastroenterology 2007;133:454-64.

79 Ates F, Francis DO, Vaezi MF. Refractory gastroesophageal reflux disease: advances and treatment. Expert Rev Gastroenterol Hepatol 2014;8:657-67.

80 Park EY, Choi MG, Baeg M, et al. The value of early wireless esophageal pH monitoring in diagnosing functional heartburn in refractory gastroesophageal reflux disease. Dig Dis Sci 2013;58:2933-9.

81 Ang D, Teo EK, Ang TL, et al. To Bravo or not? A comparison of wireless esophageal $\mathrm{pH}$ monitoring and conventional $\mathrm{pH}$ catheter to evaluate non-erosive gastroesophageal reflux disease in a multiracial Asian cohort. J Dig Dis 2010;11:19-27.

82 Boeckxstaens GE, Smout A. Systematic review: role of acid, weakly acidic and weakly alkaline reflux in gastro-oesophageal reflux disease. Aliment Pharmacol Ther 2010;32:334-43.

83 Kahrilas PJ, Boeckxstaens G, Smout AJ. Management of the patient with incomplete response to PPI therapy. Best Pract Res Clin Gastroenterol 2013;27:401-14.
84 Boeckxstaens G, El-Serag HB, Smout AJ, et al. Symptomatic reflux disease: the present, the past and the future. Gut 2014;63:1185-93.

85 Fass R, Shapiro M, Dekel R, et al. Systematic review: proton-pump inhibitor failure in gastro-oesophageal reflux disease-where next? Aliment Pharmacol Ther 2005;22:79-94.

86 Gunaratnam NT, Jessup TP, Inadomi J, et al. Sub-optimal proton pump inhibitor dosing is prevalent in patients with poorly controlled gastro-oesophageal reflux disease. Aliment Pharmacol Ther 2006;23:1473-7.

87 Fass R, Murthy U, Hayden CW, et al. Omeprazole $40 \mathrm{mg}$ once a day is equally effective as lansoprazole $30 \mathrm{mg}$ twice a day in symptom control of patients with gastro-oesophageal reflux disease (GORD) who are resistant to conventional-dose lansoprazole therapy-a prospective, randomized, multi-centre study. Aliment Pharmacol Ther 2000;14:1595-603.

88 Moayyedi P, Armstrong D, Hunt RH, et al. The gain in quality-adjusted life months by switching to esomeprazole in those with continued reflux symptoms in primary care: EncomPASS—a cluster-randomized trial. Am J Gastroenterol 2010;105:2341-6

89 Gralnek IM, Dulai GS, Fennerty MB, et al. Esomeprazole versus other proton pump inhibitors in erosive esophagitis: a meta-analysis of randomized clinical trials. Clin Gastroenterol Hepatol 2006;4:1452-8.

90 McDonagh MS, Carson S, Thakurta S. Drug class review: proton pump inhibitors: final report update 5. Portland, OR: Oregon Health \& Science University, 2009.

91 Klotz U. Clinical impact of CYP2C19 polymorphism on the action of proton pump inhibitors: a review of a special problem. Int I Clin Pharmacol Ther 2006;44:297-302.

92 Sugimoto M, Shirai N, Nishino M, et al. Comparison of acid inhibition with standard dosages of proton pump inhibitors in relation to CYP2C19 genotype in Japanese. Eur I Clin Pharmacol 2014;70:1073-8.

93 Sahara S, Sugimoto M, Uotani T, et al. Twice-daily dosing of esomeprazole effectively inhibits acid secretion in CYP2C19 rapid metabolisers compared with twice-daily omeprazole, rabeprazole or lansoprazole. Aliment Pharmacol Ther 2013:38:1129-37.

94 Sharma P, Shaheen NJ, Perez MC, et al. Clinical trials: healing of erosive oesophagitis with dexlansoprazole MR, a proton pump inhibitor with a novel dual delayed-release formulation - results from two randomized controlled studies. Aliment Pharmacol Ther 2009;29:731-41.

95 Lee RD, Mulford D, Wu J, et al. The effect of time-of-day dosing on the pharmacokinetics and pharmacodynamics of dexlansoprazole MR: evidence for dosing flexibility with a dual delayed release proton pump inhibitor. Aliment Pharmacol Ther 2010;31:1001-11.

96 Huber $\mathrm{R}$, Hartmann M, Bliesath $\mathrm{H}$, et al. Pharmacokinetics of pantoprazole in man. Int I Clin Pharmacol Ther 1996;34(Suppl 1):S7-16.

97 Yasuda S, Ohnishi A, Ogawa T, et al. Pharmacokinetic properties of E3810, a new proton pump inhibitor, in healthy male volunteers. Int I Clin Pharmacol Ther 1994;32:466-73.

98 Liu Q, Feng CC, Wang EM, et al. Efficacy of mosapride plus proton pump inhibitors for treatment of gastroesophageal reflux disease: a systematic review. World I Gastroenterol 2013:19:9111-18.

99 Cho YK, Choi MG, Park EY, et al. Effect of mosapride combined with esomeprazole improves esophageal peristaltic function in patients with gastroesophageal reflux disease: a study using high resolution manometry. Dig Dis Sci 2013;58:1035-41.

100 Futagami S, Iwakiri K, Shindo T, et al. The prokinetic effect of mosapride citrate combined with omeprazole therapy improves clinical symptoms and gastric emptying in PPI-resistant NERD patients with delayed gastric emptying. J Gastroenterol 2010;45:413-21.

101 Miyamoto M, Haruma K, Takeuchi K, et al. Frequency scale for symptoms of gastroesophageal reflux disease predicts the need for addition of prokinetics to proton pump inhibitor therapy. I Gastroenterol Hepatol 2008;23:746-51.

102 Chun BJ, Lee DS. The effect of itopride combined with lansoprazole in patients with laryngopharyngeal reflux disease. Eur Arch Otorhinolaryngol 2013;270:1385-90.

103 Wang Y, Pan T, Wang Q, et al. Additional bedtime H2-receptor antagonist for the control of nocturnal gastric acid breakthrough. Cochrane Database Syst Rev 2009:4:CD004275

104 Fackler WK, Ours TM, Vaezi MF, et al. Long-term effect of H2RA therapy on nocturnal gastric acid breakthrough. Gastroenterology 2002;122:625-32.

105 Rohof WO, Bennink RJ, Smout AJ, et al. An alginate-antacid formulation localizes to the acid pocket to reduce acid reflux in patients with gastroesophageal reflux disease. Clin Gastroenterol Hepatol 2013;11:1585-91.

106 Manabe N, Haruma K, Ito M, et al. Efficacy of adding sodium alginate to omeprazole in patients with nonerosive reflux disease: a randomized clinical trial. Dis Esophagus 2012;25:373-80.

107 Cossentino MJ, Mann K, Armbruster SP, et al. Randomised clinical trial: the effect of baclofen in patients with gastro-oesophageal reflux - a randomised prospective study. Aliment Pharmacol Ther 2012;35:1036-44. 
108 Garg SK, Gurusamy KS. Laparoscopic fundoplication surgery versus medical management for gastro-oesophageal reflux disease (GORD) in adults. Cochrane Database Syst Rev 2015;11:CD003243.

109 Galmiche JP, Hatlebakk J, Attwood S, et al. Laparoscopic antireflux surgery vs. esomeprazole treatment for chronic GORD: the LOTUS randomized clinical trial. JAMA 2011;305:1969-77.

110 Frazzoni M, Piccoli M, Conigliaro R, et al. Refractory gastroesophageal reflux disease as diagnosed by impedance-pH monitoring can be cured by laparoscopic fundoplication. Surg Endosc 2013;27:2940-6.

111 Fass R, Sifrim D. Management of heartburn not responding to proton pump inhibitors. Gut 2009;58:295-309.

112 Viazis N, Karamanolis G, Vienna E, et al. Selective-serotonin reuptake inhibitors for the treatment of hypersensitive esophagus. Therap Adv Gastroenterol 2011;4:295-300.

113 Viazis N, Keyoglou A, Kanellopoulos AK, et al. Selective serotonin reuptake inhibitors for the treatment of hypersensitive esophagus: a randomized, double-blind, placebo-controlled study. Am J Gastroenterol 2012;107:1662-7.

114 McDonald-Haile J, Bradley LA, Bailey MA, et al. Relaxation training reduces symptom reports and acid exposure in patients with gastroesophageal reflux disease. Gastroenterology 1994;107:61-9.

115 Eherer AJ, Netolitzky F, Högenauer $C$, et al. Positive effect of abdominal breathing exercise on gastroesophageal reflux disease: a randomized controlled study. Am J Gastroenterol 2012;107:372-8.

116 Klimes I, Mayou RA, Pearce MJ. Psychological treatment for atypical non-cardiac chest pain: a controlled evaluation. Psychol Med 1990;20:605-11.

117 Jones $\mathrm{H}$, Cooper P, Miller V. Treatment of non-cardiac chest pain: a controlled trial of hypnotherapy. Gut 2006;55:1403-8.

118 Kaltenbach T, Crockett S, Gerson LB. Are lifestyle measures effective in patients with gastroesophageal reflux disease? An evidence-based approach. Arch Intern Med 2006;166:965-71.

119 Ness-Jensen E, Lindam A, Lagergren J, et al. Weight loss and reduction in gastroesophageal reflux. A prospective population-based cohort study: the HUNT study. Am I Gastroenterol 2013;108:376-82.

120 Chan WW, Chiou E, Obstein KL, et al. The efficacy of proton pump inhibitors for the treatment of asthma in adults: a meta-analysis. Arch Intern Med 2011;171:620-9.

121 Chang AB, Lasserson TJ, Gaffney J, et al. Gastro-oesophageal reflux treatment for prolonged non-specific cough in children and adults. Cochrane Database Syst Rev 2011;1:CD004823.

122 Qadeer MA, Phillips CO, Lopez AR, et al. Proton pump inhibitor therapy for suspected GORD-related chronic laryngitis: a meta-analysis of randomized controlled trials. Am J Gastroenterol 2006;101:2646-54.

123 Spechler SJ, Sharma P, Souza RF, et al. American Gastroenterological Association technical review on the management of Barrett's esophagus. Gastroenterology 2011;140:e18-52; quiz e13.

124 Bennett C, Vakil N, Bergman J, et al. Consensus statements for management of Barrett's dysplasia and early-stage esophageal adenocarcinoma, based on a Delphi process. Gastroenterology 2012;143:336-46.

125 Wang KK, Sampliner RE, Practice Parameters Committee of the American College of Gastroenterology. Updated guidelines 2008 for the diagnosis, surveillance and therapy of Barrett's esophagus. Am J Gastroenterol 2008;103:788-97.

126 Smith RR, Hamilton SR, Boitnott JK, et al. The spectrum of carcinoma arising in Barrett's esophagus. A clinicopathologic study of 26 patients. Am J Surg Pathol 1984:8:563-73.

127 Skinner DB, Walther BC, Riddell RH, et al. Barrett's esophagus. Comparison of benign and malignant cases. Ann Surg 1983;198:554-65.

128 Bhat $\mathrm{S}$, Coleman HG, Yousef $F$, et al. Risk of malignant progression in Barrett's esophagus patients: results from a large population-based study. I Natl Cancer Inst 2011;103:1049-57.

129 Goda K, Singh R, Oda I, et al. Current status of endoscopic diagnosis and treatment of superficial Barrett's adenocarcinoma in Asia-Pacific region. Dig Endosc 2013;25(Suppl 2):146-50.

130 Harrison R, Perry I, Haddadin W, et al. Detection of intestinal metaplasia in Barrett's esophagus: an observational comparator study suggests the need for a minimum of eight biopsies. Am J Gastroenterol 2007:102:1154-61.

131 Kelty CJ, Gough MD, Van Wyk Q, et al. Barrett's oesophagus: intestinal metaplasia is not essential for cancer risk. Scand I Gastroenterol 2007:42:1271-4.

132 Gatenby PA, Ramus JR, Caygill CP, et al. Relevance of the detection of intestinal metaplasia in non-dysplastic columnar-lined oesophagus. Scand I Gastroenterol 2008;43:524-30.

133 Sharma P, Dent J, Armstrong D, et al. The development and validation of an endoscopic grading system for Barrett's esophagus: the Prague C \& M criteria. Gastroenterology 2006;131:1392-9.

134 Lee YC, Cook MB, Bhatia S, et al. Interobserver reliability in the endoscopic diagnosis and grading of Barrett's esophagus: an Asian multi-national study. Endoscopy 2010;42:699-704.

135 Kendall BJ, Whiteman DC. Temporal changes in the endoscopic frequency of new cases of Barrett's esophagus in an Australian health region. Am I Gastroenterol 2006;101:1178-82.
136 Xiong LS, Cui Y, Wang JP, et al. Prevalence and risk factors of Barrett's esophagus in patients undergoing endoscopy for upper gastrointestinal symptoms. J Dig Dis 2010;11:83-7.

137 Dhawan PS, Alvares JF, Vora IM, et al. Prevalence of short segments of specialized columnar epithelium in distal esophagus: association with gastroesophageal reflux. Indian J Gastroenterol 2001;20:144-7.

138 Mathew P, Joshi AS, Shukla A, et al. Risk factors for Barrett's esophagus in Indian patients with gastroesophageal reflux disease. J Gastroenterol Hepatol 2011;26:1151-6.

139 Okita K, Amano Y, Takahashi Y, et al. Barrett's esophagus in Japanese patients: its prevalence, form, and elongation. J Gastroenterol 2008;43:928-34.

140 Watari J, Hori K, Toyoshima F, et al. Association between obesity and Barrett's esophagus in a Japanese population: a hospital-based, cross-sectional study. BMC Gastroenterol 2013;13:143.

141 Park JJ, Kim JW, Kim HJ, et al. The prevalence of and risk factors for Barrett's esophagus in a Korean population: A nationwide multicenter prospective study. J Clin Gastroenterol 2009;43:907-14.

142 Rosaida MS, Goh KL. Gastro-oesophageal reflux disease, reflux oesophagitis and non-erosive reflux disease in a multiracial Asian population: a prospective, endoscopy based study. Eur I Gastroenterol Hepatol 2004;16:495-501.

143 Ang TL, Fock KM, Ng TM, et al. A comparison of the clinical, demographic and psychiatric profiles among patients with erosive and non-erosive reflux disease in a multi-ethnic Asian country. World I Gastroenterol 2005;11:3558-61.

144 Peng S, Cui Y, Xiao YL, et al. Prevalence of erosive esophagitis and Barrett's esophagus in the adult Chinese population. Endoscopy 2009;41:1011-17.

145 Tseng PH, Lee YC, Chiu HM, et al. Prevalence and clinical characteristics of Barrett's esophagus in a Chinese general population. J Clin Gastroenterol 2008;42:1074-9.

146 Corley DA, Kubo A, Levin TR, et al. Race, ethnicity, sex and temporal differences in Barrett's oesophagus diagnosis: a large community-based study, 1994-2006. Gut 2009:58:182-8.

147 Lam KD, Phan JT, Garcia RT, et al. Low proportion of Barrett's esophagus in Asian Americans. Am J Gastroenterol 2008;103:1625-30.

148 Ford AC, Forman D, Reynolds PD, et al. Ethnicity, gender, and socioeconomic status as risk factors for esophagitis and Barrett's esophagus. Am J Epidemiol 2005;162:454-60.

149 Rajendra S, Kutty K, Karim N. Ethnic differences in the prevalence of endoscopic esophagitis and Barrett's esophagus: the long and short of it all. Dig Dis Sci 2004;49:237-42.

150 Kuo CJ, Lin CH, Liu NJ, et al. Frequency and risk factors for Barrett's esophagus in Taiwanese patients: a prospective study in a tertiary referral center. Dig Dis SCi 2010;55:1337-43.

151 El-Serag HB, Kvapil P, Hacken-Bitar J, et al. Abdominal obesity and the risk of Barrett's esophagus. Am J Gastroenterol 2005;100:2151-6.

152 Akiyama T, Yoneda M, Inamori M, et al. Visceral obesity and the risk of Barrett's esophagus in Japanese patients with non-alcoholic fatty liver disease. BMC Gastroenterol 2009:9:56.

153 Andrici J, Cox MR, Eslick GD. Cigarette smoking and the risk of Barrett's esophagus: a systematic review and meta-analysis. I Gastroenterol Hepatol 2013;28:1258-73.

154 Thrift AP, Cook MB, Vaughan TL, et al. Alcohol and the risk of Barrett's esophagus: a pooled analysis from the International BEACON Consortium. Am J Gastroenterol 2014;109:1586-94.

155 Fischbach LA, Graham DY, Kramer JR, et al. Association between Helicobacter pylori and Barrett's esophagus: a case-control study. Am J Gastroenterol 2014;109:357-68.

156 Abe Y, Ohara S, Koike T, et al. The prevalence of Helicobacter pylori infection and the status of gastric acid secretion in patients with Barrett's esophagus in Japan. Am J Gastroenterol 2004;99:1213-21.

157 Verbeek RE, Spittuler LF, Peute A, et al. Familial clustering of Barrett's esophagus and esophageal adenocarcinoma in a European cohort. Clin Gastroenterol Hepatol 2014;12:1656-63.

158 Chak A, Chen Y, Vengoechea J, et al. Variation in age at cancer diagnosis in familial versus nonfamilial Barrett's esophagus. Cancer Epidemiol Biomarkers Prev 2012;21:376-83.

159 Chak A, Lee T, Kinnard MF, et al. Familial aggregation of Barrett's oesophagus, oesophageal adenocarcinoma, and oesophagogastric junctional adenocarcinoma in Caucasian adults. Gut 2002;51:323-8.

160 Su Z, Gay L, Strange A, et al. Common variants at the MHC locus and at chromosome 16q24.1 predispose to Barrett's esophagus. Nat Genet 2012:44:1131-6.

161 Ek WE, Levine DM, D'Amato M, et al. Germline genetic contributions to risk for esophageal adenocarcinoma, Barrett's esophagus, and gastroesophageal reflux. J Natl Cancer Inst 2013;105:1711-18.

162 Levine DM, Ek WE, Zhang R, et al. A genome-wide association study identifies new susceptibility loci for esophageal adenocarcinoma and Barrett's esophagus. Nat Genet 2013;45:1487-93. 
163 Ishimura N, Amano Y, Sollano JD, et al. Questionnaire-based survey conducted in 2011 concerning endoscopic management of Barrett's esophagus in East Asian countries. Digestion 2012;86:136-46.

164 Aida J, Vieth M, Ell C, et al. Palisade vessels as a new histologic marker of esophageal origin in ER specimens from columnar-lined esophagus. Am J Surg Pathol 2011;35:1140-5.

165 Hardikar S, Onstad L, Blount PL, et al. The role of tobacco, alcohol, and obesity in neoplastic progression to esophageal adenocarcinoma: a prospective study of Barrett's esophagus. PLOS ONE 2013;8:e52192.

166 Hongo M, Nagasaki Y, Shoji T. Epidemiology of esophageal cancer: orient to occident. Effects of chronology, geography and ethnicity. I Gastroenterol Hepatol 2009;24:729-35.

167 Desai TK, Krishnan K, Samala N, et al. The incidence of oesophageal adenocarcinoma in non-dysplastic Barrett's oesophagus: a meta-analysis. Gut 2012:61:970-6.

168 Anaparthy R, Gaddam S, Kanakadandi V, et al. Association between length of Barrett's esophagus and risk of high-grade dysplasia or adenocarcinoma in patients without dysplasia. Clin Gastroenterol Hepatol 2013;11:1430-6.

169 Streitz JM Jr, Andrews CW Jr, Ellis FH Jr. Endoscopic surveillance of Barrett's esophagus. Does it help? J Thorac Cardiovasc Surg 1993;105:383-7; discussion 387-8.

170 Peters JH, Clark GW, Ireland AP, et al. Outcome of adenocarcinoma arising in Barrett's esophagus in endoscopically surveyed and nonsurveyed patients. J Thorac Cardiovasc Surg 1994;108:813-21.

171 van Sandick JW, van Lanschot JJ, Kuiken BW, et al. Impact of endoscopic biopsy surveillance of Barrett's oesophagus on pathological stage and clinical outcome of Barrett's carcinoma. Gut 1998;43:216-22.

172 Corley DA, Levin TR, Habel LA, et al. Surveillance and survival in Barrett's adenocarcinomas: a population-based study. Gastroenterology 2002;122:633-40.

173 Cooper GS, Yuan Z, Chak A, et al. Association of pre-diagnosis endoscopy with stage and survival in adenocarcinoma of the esophagus and gastric cardia. Cancer 2002:95:32-8.

174 Fountoulakis A, Zafirellis KD, Dolan K, et al. Effect of surveillance of Barrett's oesophagus on the clinical outcome of oesophageal cancer. $\mathrm{Br} J$ Surg 2004;91:997-1003.

175 Rubenstein JH, Sonnenberg A, Davis J, et al. Effect of a prior endoscopy on outcomes of esophageal adenocarcinoma among United States veterans. Gastrointest Endosc 2008:68:849-55.

176 Corley DA, Mehtani K, Quesenberry C, et al. Impact of endoscopic surveillance on mortality from Barrett's esophagus-associated esophageal adenocarcinomas. Gastroenterology 2013;145:312-19.

177 Verbeek RE, Leenders M, Ten Kate FJ, et al. Surveillance of Barrett's esophagus and mortality from esophageal adenocarcinoma: a population-based cohort study. Am J Gastroenterol 2014;109:1215-22.

178 Gordon LG, Mayne GC, Hirst NG, et al. Cost-effectiveness of endoscopic surveillance of non-dysplastic Barrett's esophagus. Gastrointest Endosc 2014;79:242-56.

179 Evans JA, Early DS, Fukami N, et al. The role of endoscopy in Barrett's esophagus and other premalignant conditions of the esophagus. Gastrointest Endosc 2012;76:1087-94.

180 Thrift AP, Kendall BJ, Pandeya N, et al. A model to determine absolute risk for esophageal adenocarcinoma. Clin Gastroenterol Hepatol 2013;11:138-44.

181 Rubenstein JH, Morgenstern H, Appelman H, et al. Prediction of Barrett's esophagus among men. Am J Gastroenterol 2013;108:353-62.

182 Liu X, Wong A, Kadri SR, et al. Gastro-esophageal reflux disease symptoms and demographic factors as a pre-screening tool for Barrett's esophagus. PLoS One 2014:9:e94163.

183 Thota PN, Zuccaro G Jr, Vargo JJ II, et al. A randomized prospective trial comparing unsedated esophagoscopy via transnasal and transoral routes using a 4-mm video endoscope with conventional endoscopy with sedation. Endoscopy 2005:37:559-65.

184 Jobe BA, Hunter JG, Chang EY, et al. Office-based unsedated small-caliber endoscopy is equivalent to conventional sedated endoscopy in screening and surveillance for Barrett's esophagus: a randomized and blinded comparison. Am J Gastroenterol 2006;101:2693-703.

185 Saeian K, Staff DM, Vasilopoulos S, et al. Unsedated transnasal endoscopy accurately detects Barrett's metaplasia and dysplasia. Gastrointest Endosc 2002;56:472-8.

186 Nakos G, Karagiannis S, Ballas S, et al. A study comparing tolerability, satisfaction and acceptance of three different techniques for esophageal endoscopy: sedated conventional, unsedated peroral ultra thin, and esophageal capsule. Dis Esophagus 2009:22:447-52.

187 Lin OS, Schembre DB, Mergener K, et al. Blinded comparison of esophageal capsule endoscopy versus conventional endoscopy for a diagnosis of Barrett's esophagus in patients with chronic gastroesophageal reflux. Gastrointest Endosc 2007;65:577-83.

188 Gupta M, Beebe TJ, Dunagan KT, et al. Screening for Barrett's esophagus: results from a population-based survey. Dig Dis Sci 2014;59:1831-50.
189 Singh S, Garg SK, Singh PP, et al. Acid-suppressive medications and risk of oesophageal adenocarcinoma in patients with Barrett's oesophagus: a systematic review and meta-analysis. Gut 2014;63:1229-37.

190 Hvid-Jensen F, Pedersen L, Funch-Jensen P, et al. Proton pump inhibitor use may not prevent high-grade dysplasia and oesophageal adenocarcinoma in Barrett's oesophagus: a nationwide study of 9883 patients. Aliment Pharmacol Ther 2014;39:984-91.

191 Brown CS, Lapin B, Wang C, et al. Predicting regression of Barrett's esophagus: results from a retrospective cohort of 1342 patients. Surg Endosc 2014:28:2803-7.

192 Zhang S, Zhang XQ, Ding XW, et al. Cyclooxygenase inhibitors use is associated with reduced risk of esophageal adenocarcinoma in patients with Barrett's esophagus: a meta-analysis. Br J Cancer 2014;110:2378-88.

193 Das D, Chilton AP, Jankowski JA. Chemoprevention of oesophageal cancer esophagus and the AspECT trial. Recent Results Cancer Res 2009;181:161-9.

194 Curvers WL, ten Kate FJ, Krishnadath KK, et al. Low-grade dysplasia in Barrett's esophagus: overdiagnosed and underestimated. Am J Gastroenterol 2010;105:1523-30.

195 Skacel M, Petras RE, Rybicki LA, et al. p53 expression in low grade dysplasia in Barrett's esophagus: correlation with interobserver agreement and disease progression. Am J Gastroenterol 2002;97:2508-13.

196 Peters FP, Brakenhoff KP, Curvers WL, et al. Histologic evaluation of resection specimens obtained at 293 endoscopic resections in Barrett's esophagus. Gastrointest Endosc 2008:67:604-9.

197 Wolfsen HC, Crook JE, Krishna M, et al. Prospective, controlled tandem endoscopy study of narrow band imaging for dysplasia detection in Barrett's esophagus. Gastroenterology 2008;135:24-31.

198 Mannath J, Subramanian V, Hawkey CJ, et al. Narrow band imaging for characterization of high grade dysplasia and specialized intestinal metaplasia in Barrett's esophagus: a meta-analysis. Endoscopy 2010;42:351-9.

199 Sharma P, Hawes RH, Bansal A, et al. Standard endoscopy with random biopsies versus narrow band imaging targeted biopsies in Barrett's oesophagus: a prospective, international, randomised controlled trial. Gut 2013;62:15-21.

200 Song J, Zhang J, Wang J, et al. Meta-analysis of the effects of endoscopy with narrow band imaging in detecting dysplasia in Barrett's esophagus. Dis Esophagus 2015;28:560-6.

201 Osawa H, Yamamoto H, Yamada N, et al. Diagnosis of endoscopic Barrett's esophagus by transnasal flexible spectral imaging color enhancement. J Gastroenterol 2009:44:1125-32.

202 Camus M, Coriat R, Leblanc S, et al. Helpfulness of the combination of acetic acid and FICE in the detection of Barrett's epithelium and Barrett's associated neoplasias. World J Gastroenterol 2012;18:1921-5.

203 Hvid-Jensen F, Pedersen L, Drewes AM, et al. Incidence of adenocarcinoma among patients with Barrett's esophagus. N Engl J Med 2011;365:1375-83.

204 de Jonge PJ, van Blankenstein M, Looman CW, et al. Risk of malignant progression in patients with Barrett's oesophagus: a Dutch nationwide cohort study. Gut 2010;59:1030-6.

205 Wani S, Falk G, Hall M, et al. Patients with nondysplastic Barrett's esophagus have low risks for developing dysplasia or esophageal adenocarcinoma. Clin Gastroenterol Hepatol 2011;9:220-7.

206 Gaddam S, Singh M, Balasubramanian G, et al. Persistence of nondysplastic Barrett's esophagus identifies patients at lower risk for esophageal adenocarcinoma: results from a large multicenter cohort. Gastroenterology 2013;145:548-53.e1

207 Kastelein F, van Olphen S, Steyerberg EW, et al. Surveillance in patients with long-segment Barrett's oesophagus: a cost-effectiveness analysis. Gut 2015:64:864-71.

208 Vennalaganti P, Kanakadandi V, Goldblum JR, et al. Revised classification of low grade dysplasia (LGD) in Barrett's esophagus (BE): time to rethink the role of LGD as a risk stratification strategy in BE. Gastroenterology 2014;146(Suppl 1): S-147.

209 Singh S, Manickam P, Amin AV, et al. Incidence of esophageal adenocarcinoma in Barrett's esophagus with low-grade dysplasia: a systematic review and meta-analysis. Gastrointest Endosc 2014;79:897-909.e4; quiz 983.e1, 983.e3.

210 Phoa KN, van Vilsteren FG, Weusten BL, et al. Radiofrequency ablation vs endoscopic surveillance for patients with Barrett esophagus and low-grade dysplasia: a randomized clinical trial. JAMA 2014;311:1209-17.

211 Prasad GA, Wu TT, Wigle DA, et al. Endoscopic and surgical treatment of mucosal (T1a) esophageal adenocarcinoma in Barrett's esophagus. Gastroenterology 2009;137:815-23.

212 Wu J, Pan YM, Wang TT, et al. Endotherapy versus surgery for early neoplasia in Barrett's esophagus: a meta-analysis. Gastrointest Endosc 2014;79:233-41.e2.

213 Pech O, Bollschweiler E, Manner H, et al. Comparison between endoscopic and surgical resection of mucosal esophageal adenocarcinoma in Barrett's esophagus at two high-volume centers. Ann Surg 2011;254:67-72.

214 Konda VJ, Ross AS, Ferguson MK, et al. Is the risk of concomitant invasive esophageal cancer in high-grade dysplasia in Barrett's esophagus overestimated? Clin Gastroenterol Hepatol 2008;6:159-64. 
215 Prasad GA, Wang KK, Buttar NS, et al. Long-term survival following endoscopic and surgical treatment of high-grade dysplasia in Barrett's esophagus. Gastroenterology 2007;132:1226-33.

216 Haidry RJ, Dunn JM, Butt MA, et al. Radiofrequency ablation and endoscopic mucosal resection for dysplastic Barrett's esophagus and early esophageal adenocarcinoma: outcomes of the UK National Halo RFA Registry. Gastroenterology 2013;145:87-95.

217 Gupta M, lyer PG, Lutzke L, et al. Recurrence of esophageal intestinal metaplasia after endoscopic mucosal resection and radiofrequency ablation of Barrett's esophagus: results from a US Multicenter Consortium. Gastroenterology 2013;145:79-86.e1.

218 Yaghoobi M, Farrokhyar F, Yuan Y, et al. Is there an increased risk of GORD after Helicobacter pylori eradication? A meta-analysis. Am I Gastroenterol 2010;105:1007-13.

219 Qian B, Ma S, Shang L, et al. Effects of Helicobacter pylori eradication on gastroesophageal reflux disease. Helicobacter 2011;16:255-65.

220 Saad AM, Choudhary A, Bechtold ML. Effect of Helicobacter pylori treatment on gastroesophageal reflux disease (GORD): meta-analysis of randomized controlled trials. Scand I Gastroenterol 2012;47:129-35.

221 Xie T, Cui X, Zheng H, et al. Meta-analysis: eradication of Helicobacter pylori infection is associated with the development of endoscopic gastroesophageal reflux disease. Eur J Gastroenterol Hepatol 2013;25:1195-205.
222 Lee YC, Chen TH, Chiu HM, et al. The benefit of mass eradication of Helicobacter pylori infection: a community-based study of gastric cancer prevention. Gut 2013;62:676-82.

223 Hamada H, Haruma K, Mihara M, et al. High incidence of reflux oesophagitis after eradication therapy for Helicobacter pylori: impacts of hiatal hernia and corpus gastritis. Aliment Pharmacol Ther 2000;14:729-35.

224 Derakhshan MH, Arnold M, Brewster DH, et al. Worldwide inverse association between gastric cancer and esophageal adenocarcinoma suggesting a common environmental factor exerting opposing effects. Am I Gastroenterol 2016;111:228-39.

225 Ashida K, Sakurai Y, Hori T, et al. Randomised clinical trial: vonoprazan, a novel potassium-competitive acid blocker, vs. lansoprazole for the healing of erosive oesophagitis. Aliment Pharmacol Ther 2016;43:240-51.

226 Bennett C, Moayyedi P, Corley DA, et al. BOB CAT: a large-scale r eview and Delphi consensus for management of Barrett's esophagus with no dysplasia, indefinite for, or low-grade dysplasia. Am J Gastroenterol 2015;110:662-82.

227 Whiteman DC, Appleyard M, Bahin FF, et al. Australian clinical practice guidelines for the diagnosis and management of Barrett's esophagus and early esophageal adenocarcinoma. J Gastroenterol Hepatol 2015;30:804-20. 